Illinois State University

ISU ReD: Research and eData

Theses and Dissertations

4-14-2016

\title{
Why Are Students Doing Research? Examining The Motivation Of Students Involved In Undergraduate Research Programs
}

Andrew Layne McDevitt

Illinois State University, amcdevi@ilstu.edu

Follow this and additional works at: https://ir.library.illinoisstate.edu/etd

Part of the Biology Commons, Ecology and Evolutionary Biology Commons, and the Science and Mathematics Education Commons

\section{Recommended Citation}

McDevitt, Andrew Layne, "Why Are Students Doing Research? Examining The Motivation Of Students Involved In Undergraduate Research Programs" (2016). Theses and Dissertations. 528.

https://ir.library.illinoisstate.edu/etd/528

This Thesis is brought to you for free and open access by ISU ReD: Research and eData. It has been accepted for inclusion in Theses and Dissertations by an authorized administrator of ISU ReD: Research and eData. For more information, please contact ISUReD@ilstu.edu. 
WHY ARE STUDENTS DOING RESEARCH? EXAMINING THE MOTIVATION OF

STUDENTS INVOLVED IN UNDERGRADUATE

RESEARCH PROGRAMS

Andrew L. McDevitt

\section{Pages}

Use of self-determination theory (SDT) within the science classroom focuses primarily on ways to integrate intrinsic motivation into students' identity. Experiential learning plays a large role in promoting learning by shaping students' interests, identity, and intrinsic aspirations. This phenomenological research study sought to understand how experiential learning experiences helped influence career aspirations of graduate students within ecological disciplines. By determining how their experiences met three basic psychological needs outlined by SDT (competence, autonomy, and relatedness), we were able to examine which regulators drove motivation.

In the qualitative pilot study, participants developed a genuine enjoyment and appreciation for their discipline as they began engaging in more complex research. As interest grew, so did levels of competence and autonomy. Students were able to apply their experiences in novel ways which enabled them to see the connectivity of their discipline and develop internal aspirations for science. In addition to aspirations 
supported by experiential learning opportunities, mentorship, family/cultural support, and the desire for a work-life balance further shaped their career aspirations and satisfied the basic need for relatedness. This boost of confidence and sense of belonging helped participants shed doubts and other external pressures that allowed students to believe that they might not belong in science. Finding from this pilot study helped inform the development of a larger quantitative survey.

The Biological Research Experience Survey (BRES) sought to understand how the basic psychological needs of self-determination theory are being satisfied during undergraduate research experience. Using a numerous previously validated instruments from the SDT and science education literature, the BRES connected a number of underlying constructs through exploratory factor analysis. Five factors emerged, accounting for $62.19 \%$ of the variance, and were named Scientific Identity, Mentor Support, Research Motivations, and Science Degree Aspirations. The alignment of these latent factors with SDT further suggests that this framework may be useful for capturing the variation associated with these research experiences. The design of this survey helps account for the within-subject variability, allows for meaningful conclusions with smaller sample sizes, and may prove a valuable evaluation tool small programs such as UREs. Further implementation of this framework may help identify resources that motivate students toward STEM careers and enable students, and particularly those from historically under-represented groups to reach their potential in STEM disciplines.

KEYWORDS: Science Education, Self-determination Theory, Motivation, Undergraduate Research Experiences, Environmental Education 
WHY ARE STUDENTS DOING RESEARCH? EXAMINING THE MOTIVATION OF

STUDENTS INVOLVED IN UNDERGRADUATE

RESEARCH PROGRAMS

ANDREW L. MCDEVITT

A Thesis Submitted in Partial

Fulfillment of the Requirements

for the Degree of

MASTER OF SCIENCE

School of Biological Sciences

ILLINOIS STATE UNIVERSITY

2016 
(C) 2016 Andrew L. McDevitt 
WHY ARE STUDENTS DOING RESEARCH? EXAMINING THE MOTIVATION OF STUDENTS INVOLVED IN UNDERGRADUATE

RESEARCH PROGRAMS

ANDREW L. MCDEVITT

COMMITTEE MEMBERS:

Rebekka D. Gougis, Chair

Diane L. Byers

Cynthia J. Moore 


\section{ACKNOWLEDGMENTS}

The writer wishes to thank the Illinois State University School of Biological Sciences, his committee for their support throughout the past two years, and all of the anonymous participants who took their time to contribute to these projects. Additionally, Wendy Troxel was instrumental in helping plan the qualitative techniques used during chapter 1 , and this process was very informative in helping shape and define the quantitative study. The success of this second study would not have been successful without the support of eight undergraduate research program coordinators who helped distribute the survey to their students.

A. L. M. 


\section{CONTENTS}

\section{Page}

ACKNOWLEDGMENTS $\quad$ i

CONTENTS $\quad$ ii

TABLES $\quad$ V

FIGURES

I. SELF-DETERMINATION THEORY AS A LENS FOR PROMOTING SCIENTIFIC IDENTITY AND RETENTION:

A PILOT STUDY 1

Introduction 1

Problem Statement 2

Research Questions 3

$\begin{array}{ll}\text { Methods } & 3\end{array}$

Participant Recruitment 3

Participant Profile 4

Qualitative Procedures $\quad 5$

Data Analysis 6

$\begin{array}{ll}\text { Results } & 7\end{array}$

How Do Biology Graduate Students Describe Past

Hands-on Learning Experiences? 7

What Are the Career Aspirations of These Graduate Students?

How Have Hands-On Learning Experiences Shaped Their Career Aspirations?

How Have Other Types of Experiences Shaped Their Career Aspirations? 20

How Do Their Aspirations Fit Into the Framework of Self-Determination Theory? 
Discussion

How Have Experiential Learning Opportunities

Shaped Their Career Aspirations?

How Have Other Types of Experiences Shaped

Their Career Aspirations?

How Does SDT Explain Their Aspirations?

Implications

Acknowledgments

References

II. EXAMINING THE MOTIVATION OF STUDENTS

INVOLVED IN BIOLOGICAL RESEARCH PROGRAMS

Introduction

Theoretical Framework

Aim of the Study

Methods

Survey Construction

Demographic Information

Motivation Towards Research Experience Scale (MTRES)

Perceptions of Mentor Scale (POMS)

Aspiration Index (AI)

Persistence in Science Scale (PSS)

Colorado Learning Attitudes About Science Survey

for use in Biology (CLASS-Bio)

51

Participants and Data Collection

Data Analysis

Results

Biological Research Experience Model 54

Differences Based Upon Experience Level 55

$\begin{array}{ll}\text { Discussion } & 56\end{array}$

Relationship of Factors $\quad 56$

Alignment of SDT and Student Experiences $\quad 57$

Further Applications $\quad 60$

$\begin{array}{ll}\text { Acknowledgments } & 61\end{array}$ 
$\begin{array}{ll}\text { References } & 61\end{array}$

$\begin{array}{lll}\text { III. FUTURE DIRECTIONS } & 71\end{array}$

$\begin{array}{ll}\text { References } & 73\end{array}$

$\begin{array}{ll}\text { APPENDIX A: Guiding Questions for Interviews } & 74\end{array}$

APPENDIX B: Biological Research Experience Survey Description 75

APPENDIX C: Correlation Matrix for Exploratory Factor Analysis $\quad 87$ 


\section{TABLES}

Table

1. Summary of Category Variables
Page

67 


\section{FIGURES}

Figure $\quad$ Page

1. Demographic Information 68

2. Path Diagram of Biological Research Experience Survey
(MTRES).

3. Comparison of Latent Variables Based on Class Standing 70 


\section{CHAPTER I}

\section{SELF-DETERMINATION THEORY AS A LENS FOR PROMOTING SCIENTIFIC IDENTITY AND RETENTION: A PILOT STUDY}

Introduction

Science, technology, engineering and mathematics (STEM) fields are known to be a primary driver of technological advancements and economic success which creates an ever-increasing demand for qualified employees for entering these areas (Brown, Hansen-Brown, \& Conte, 2011; Rothwell, 2013). However, there is a growing achievement gap in these fields which has left many individuals, especially students from underrepresented groups, not pursuing and succeeding in STEM fields comparable to mainstream students (Gazley et al., 2014; Hill, Corbett, \& St. Rose, 2010; Rothwell, 2013; Sian, 2013; Wang \& Degol, 2013). As higher education provides the primary source of training for these careers (Rothwell, 2013), there have been many strategies proposed to increase student retention within these disciplines (Boettcher, 2014; Brown et al., 2011; Gazley et al., 2014; Hill et al., 2010; Rothwell, 2013). One of the strategies to decrease the skills gap is to incorporate more hands-on learning opportunities (Gazley et al., 2014; Rothwell, 2013). This study seeks to use the lens of self-determination theory to examine how basic psychological needs are met through these experiences and how those needs help regulate motivation and aspirations towards a STEM career. 


\section{Problem Statement}

The purpose of this qualitative pilot study was to explore how experiential learning, specifically lab and fieldwork, may motivate students towards a career in the ecological or environmental sciences. This study focused on graduate students pursuing a graduate degree in an ecological science with the assumption that they have engaged in experiential learning through coursework, independent study, or employment that are relevant to their career path. We used the lens of self-determination theory (SDT), a theory of human motivation and personality (Deci \& Ryan, 2000, 2008; Vansteenkiste \& Ryan, 2013) to examine student motivations regarding their career. SDT posits "the acquisition and maintenance of identities is a dynamic process in which identities are developed and adopted to satisfy the basic psychological needs for autonomy, competence, and relatedness and thus may be understood as a complex expression of the interaction between needs and social context affordances" (Vlachopoulos, Kaperoni, \& Moustaka, 2011, p. 266). These factors that help shape the notion of life goals and are generalized into two categories: intrinsic aspirations and extrinsic aspirations (Deci \& Ryan, 2000, 2008; Vansteenkiste \& Ryan, 2013).

Use of SDT within the classroom primarily focuses on ways to integrate intrinsic motivation into students' identity (Kusurkar, Croiset, \& Cate, 2011; Mackenzie, Son, \& Hollenhorst, 2014; Oguz, 2013; Tabachnick, Miller, \& Relyea, 2008). Experiential learning plays a large part in helping to promote learning (Buckley, 2010; Fechheimer, Webber, \& Kleiber, 2011; Gazley et al., 2014; Korkmaz, Cole, \& Buckley, 2011) by shaping students' interests, identity and intrinsic aspirations (Brown et al., 2011; Wang \& Eccles, 2013). Although science presents students with challenging concepts, and may 
sometimes conflict with personal and cultural beliefs, transformative experiences have been shown to help facilitate conceptual change (Heddy \& Sinatra, 2013).

\section{Research Questions}

Understanding of how undergraduate research experiences impact career or discipline choice may inform the science education community about which undergraduate experiences are seminal in the development of scientific identity in the ecological sciences. This study addresses three research questions:

1. How do biology graduate students describe past hands-on learning experiences?

2. What are the career aspirations of these graduate students?

3. How have experiential learning opportunities shaped their career aspirations?

4. How have other types of experiences shaped their career aspirations?

5. How does SDT explain their aspirations?

\section{Methods}

This phenomenological research study sought to understand how experiential learning experiences help to influence career aspirations of graduate students within ecological disciplines. Graduate students were interviewed using a semi-structured protocol designed to prompt them to elaborate on experiences and remain within the study's foci.

\section{Participant Recruitment}

All participants were enrolled graduate students at a large, public university in the Midwestern U.S. Graduate, rather than undergraduate, students were chosen with the assumption that they are more likely to have experiences (i.e., upper-level coursework, 
independent study, employment, etc.) that were experiential and relevant to their career goals. A decision to focus on ecologically related research interests was driven by the interdisciplinary nature of ecology and tendency for researchers to combine both lab and field research techniques. The broad size and scope of this discipline make it difficult to compartmentalize and therefore a broad lens is needed to study these varied experiences.

Participants were recruited from a pool of approximately 60 biology graduate students via a departmental listserv and recruitment letters. No monetary incentives were offered. Interviews were advertised as lasting 45-60 minutes. Sixteen potential participants (11 ecology, three molecular/cell biology, one medicine, one neuroscience) responded to initial recruitment letters. Due to projects goals, four ecology students were purposely selected (Merriam, 2009). Once participants gave consent, audio recordings of the interviews were collected and used to analyze responses. In addition to audio recording, the interviewer kept notes on the general atmosphere and participants' emotions throughout the interviews.

\section{Participant Profile}

"Abby" is a first-year master's student. While in high school, Abby was dual enrolled at a local community college where later earned her associate's degree. She then transferred to a four-year school to earn her bachelor's in biology. Her research interests include ecology and conservation. Her career goals are rather broad, however, she wants to work in conservation. 
"Brittany" is a first-year master's student. Brittany earned her bachelor's in biology/psychology at a large public university. Her research interests focus on animal behavior and is currently undecided on her particular career path.

"Colin" recently received his doctorate and is transitioning into a role as a postdoc. Colin earned his bachelor's in biology at a small liberal arts college before continuing with his graduate studies. His research interests are in ecology and evolution, and his career goals are to continue with academic research, ideally as a faculty member.

"Darcy" is a second-year master's student. Darcy attended a mid-size research intensive institution where she earned a bachelor's in biology. She held a variety of positions as wildlife technicians as well as in environmental education before returning for graduate study. Her discipline interests are in ecology and conservation. Darcy wishes to go back to similar wildlife positions but with a more leadership role.

\section{Qualitative Procedures}

The interview protocol was semi-structured in design and allowed the interviewer to respond to the participants' perspective on their experiences (Merriam, 2009). Questions were crafted in order prevent participants from receiving cues about any idealized responses embedded within the question (Dana, Dana, Kelsay, Thomas, \& Tippins, 1992). These precautions were aimed at obtaining the participants' initial responses, which were more likely to reveal experiences most relevant to them. This study focused on participants being able to not only describe the outcomes of their experiences but also try to identify how those experiences shaped their perceptions of the field. The participants were the ones who experienced what they described, and attention 
was directed towards the experiences in which they selected as important, as well as the ways in which they chose to construct their responses. How they chose to perceive these experiences likely influenced their intrinsic motivation (Deci \& Ryan, 2000). Although we were concerned about the accuracy of their narratives, the purpose of the study was to understand how participants made sense of their undergraduate career, created meaning from their experiences, and interpreted the outcomes of their experiences.

\section{Data Analysis}

Analysis began with a verbatim transcription of the recorded using HyperTRANSCRIBE v.1.5.3 software; pseudonyms were assigned during transcription. The initial coding process for this grounded theory analysis (Strauss \& Corbin, 1998) began by organizing participant responses, aided by HyperRESEARCH 3.0.3, according to our five primary research questions. Then transcripts were then coded by hand using an open-coding method (Strauss \& Corbin, 1998) to develop and identify emerging themes. Participant transcripts were reviewed in their entirety for each research question. As suggested by Caudle (2004), we referenced a theoretical concept map to ensure that the data collection and analysis were on target with research questions. If a novel theme emerged during a review of one of the transcripts, previous transcripts would be examined again to check if the concept was also present but previously undetected. As coding progressed, we sought an adequate representation of axial codes with the goal of reaching theoretical saturation (Guest, Bunce, \& Johnson, 2006), however, we acknowledged that a sample size of four may not reach complete saturation. Nonetheless, some repetitive themes were inferable and then recoded to selective SDT constructs such as autonomy, competence, and relatedness. 


\section{Results}

\section{How Do Biology Graduate Students Describe Past Hands-on Learning Experiences?}

Participants revealed what they thought of when describing hands-on experiences, as well as how they interpreted their experiences. These responses were their initial reactions to these ideas and did not represent everything the participant may think or feel, however, they do reveal the topics most relevant to them at the time.

Defining Hands-on Experiences. Participants varied in the level of which they were able to describe what hands-on experiences meant for them. Most were able to give examples of specific types of experiences that they associate with hands-on learning. Except Colin, none of the participants expanded beyond the point that hands-on learning was an active process.

Brittany's initial ideas about what hands-on learning was "taking a lab course, working in a lab, going and doing field work, field course, that sort of thing. Doing a thesis". Although she seemed to struggle to find a way to define what it meant to her, she was able to describe her experiences in these areas with much more detail.

Abby was able to go into a little bit more detail about hands-on learning being an active process, but similar to Brittany, most of her description consisted of naming experiences that she could relate to personally. She described a dynamic view of handson learning; "you're not just sitting there learning about it, but you're like physically doing it with your hands". She gave examples such as plating microbes in a microbiology classroom and going on a forest field trip during an ecology class. Although she initially had trouble describing what she thought I was looking for, she said that the best examples that she could give were related to her experiences. 
Similar to Abby, Darcy had always associated certain activities with hands-on learning but hadn't thought about it in a conceptual way. Her initial description was it was "the idea of being able to get your hands dirty, being involved in doing an experiment". She figured that hands-on learning might take a different direction depending upon the setting and who was participating, but mentioned that regardless of the situation it was more than just simply learning about the material. Again, an essential part of her experience was being actively involved in the process.

Colin seemed to have the clearest understanding of the term. He used the term experiential learning to describe the idea of hands-on experiences. He believes that to be successful, students should "first learn principles in the classroom and then actually apply those in a sort of hands-on sense in perhaps a field or a laboratory setting." He believes that these experiences can happen in either a field or laboratory setting and have a goal, possibly testing a hypothesis, which expands upon classroom knowledge.

Describing Their Experiences. For the participants, the experiences that they discussed were almost all associated with undergraduate or graduate level education, although there was mention of internship and employment experiences. Most of these experiences described took place within a lab or field research setting. They were mainly associated with specific courses or independent study with an emphasis on formal scientific inquiry.

Colin mentions that the first time he remembers conducting significant hands-on experiences outside the classroom was in during his experience as an undergraduate. Although he doesn't necessarily describe any of his hands-on experiences with much detail, he says these lab and field experiences opened him up to the value of research. He 
liked that he could explore his innate sense of curiosity and actively participates in science.

Brittany's descriptions of her hands-on research experiences were also positive. She gave two primary examples of research projects: one for a class, the other for her undergraduate thesis. For her, these experiences gave her a chance to "go through the whole process and see kind of how research works". Brittany noted that neither project rigorously focused on all of the parts of the scientific method, but what they did concentrate on helped focus the material and contributed to her overall understanding of research. She noted that by breaking it down and focusing on specific parts allowed her to reach a deeper understanding within the timeframe of a single semester or year.

Abby had a broad range of hands-on learning experiences in the fields of microbiology and ecology and probably discussed her views of these with the most detail. She had a noticeable spike in enthusiasm when she was talking about these experiences, and it was clear that she enjoyed the opportunities. These primarily consisted of lab courses, field trips, internships, and even some independent research. All of these handson experiences that she discussed were during her undergraduate career. Although she enjoyed both types of experiences, it is important to note that she chose a path towards ecology rather than microbiology (the reasons will be explored further in the following research questions). Within ecology, one of her most memorable experiences was in an ecology class where lab activities were split between in-class simulations and outdoor data collection. She specifically enjoyed the data collection compared to a computer simulation stating "I get the opportunity to do it myself, so it feels more real to me." This allowed her to apply the theories and knowledge that she learned in class and helped 
solidify the concepts for her. Through the use of hands-on experiences in the classroom, she felt like she gained a better understanding of the concepts.

Although Darcy expressed a positive attitude towards her experiences, similar to the other three participants, she was the only one to mention some negative aspects of these experiences. Darcy has had a large number of hands-on ecology experiences in some different settings (an internship at a zoo, academic research projects, a government sponsored field research internship, and as a naturalist) and seemed to find positives and negatives with each of them. From the way she described them, Darcy seemed to enjoy and appreciate each opportunity. However, she did note in a few of her experiences she felt frustrated about administrative issues. These frustrations both occurred outside of the academic setting while working at the government internship as well as in the naturalist position. In both instances, these mild frustrations revolved around the amount of say she had towards what or how she was doing things. This gave her a greater appreciation for some of the other opportunities that she had and showed her the importance of the principles learned in academic research. For Darcy, these experiences went beyond simply academics and taught her things about herself that are nearly impossible to learn in a traditional lecture setting.

\section{What Are the Career Aspirations of These Graduate Students?}

The purpose of this question was to identify where the participants saw themselves within a particular biological discipline as well as their aspirations for a potential career within that discipline. The participant selection process favored those whose research interests were within an ecologically or environmentally related field. Although it is expected to see that all four participants are interested in these disciplines, 
it is important to note that each participant has a slightly different idea of what that means for them. These distinctions are important to note as they also shape how the participant envisions a career within an environmental discipline.

Discipline Choice. Abby was interested in microbiology as an undergraduate; however in her senior year, while she was in the middle of applying to graduate programs, she decided to make the switch to ecology and conservation. It appears as if she has a very applied vision of conservation. She was able to identify certain ecological issues and saw the discipline as a way protecting and restoring nature from anthropogenic effects.

Brittany's interests are in animal behavior. Although initially expressing interests in medicine, once she entered college she focused more towards biology/psychology. She appreciated how different genetic and environmental mechanisms could influence behavior. Although she views the discipline as primarily academic, the information gained can be easily applied to more real world circumstances.

Colin initially expressed interest in medicine and other science disciplines as an undergrad, however, he realized early on that he had a passion for ecology. Though the course of his graduate career, he has focused his desires towards studying ecological phenomena in natural populations. He is very much interested in the specific mechanisms that exist and believes that studying how they occur in nature is the best way to develop a complete picture.

Darcy developed a passion for ecology early on in her undergraduate career and had some interests within the discipline. She describes conservation as "essentially making sure that all the other species that we share the planet with have a place." 
Although she recognizes that there are many different approaches to conservation, she believes that one of the roles of science is to advocate for nature.

Career Aspirations. When discussing her career aspirations, Abby was admittedly very unclear of which direction she wanted to take within conservation. She attributed a lot of this indecision to being new to the discipline saying: "I think I am still going through that process of establishing that this is where I want to be [within conservation] and getting that experience now." For her, a conservation career would involve protecting and preserving endangered and threatened species. To move forward within this career path, she feels that would need to focus on a particular taxon or subject, however at this point in her academic career she does not feel like she has a broad enough knowledge of the discipline to determine her ideal career choice.

Brittany is also unsure about where her interest in animal behavior will specifically guide her career. She likes the "idea of helping people become more scientifically literate; that's something that I kind of tied into the research". A job that incorporates both research and practical application makes her feel like she's making a difference in promoting the field as a whole, rather than just on high profile topics. She acknowledges that not everyone is a scientist and may not understand the importance of this type of scientific research. Her personality and aspirations align here with a career in which she can share her specialized interests to contribute to general public wellbeing. One idea that she had includes a return to her home country and work for their version of the Environmental Protection Agency. Although she was able to give a specific example of a potential aspiration, she was quick to mention that she still did not know if this was the exact path she wanted to take. 
Colin has a clear idea of what he intends to study within the field of ecology. He has a strong desire to continue as a researcher. However, he did not explicitly state whether he envisioned his work in an academic or governmental setting. He feels very equipped to pursue this goal and is currently transitioning into a post-doctorate role where he will continue with his same line of research. Although he did not provide too many details about specific experiences that helped him feel this way, he said that his years of experience as a whole built his knowledge base and reconfirmed that this is the correct path for him.

Although she is not entirely sure what she wants to focus on, Darcy knows she likes working with animals in both an educational and research setting. Ideally, she would like to see herself in a government setting with either the Fish and Wildlife Service or the National Park Service as a biologist. Although flexible for whatever direction she may take, she wants a position where she has a direct say in the protocols that she does. This was one of the main reasons that she felt like she needed to get at least a master's degree in biology. Darcy has expressed interest in perusing a $\mathrm{PhD}$ but has decided to hold off a little longer and settle her family for a little while.

\section{How Have Hands-on Learning Experiences Shaped Their Career Aspirations?}

Most of the themes that emerged revolved around the individual's development which included the following aspects: enjoyment of the discipline, faculty mentorship, and their ability to identify with a career. The participants mentioned an increased satisfaction which seemed to stem from the active use of the material. This satisfaction often lead to higher engagement which combined with direction from faculty and mentors help them identify with a career. 
Enjoyment of the Discipline. Before becoming formally involved in the field of animal behavior, Brittany expressed that she would hear about similar subjects in the news but, due to a lack of understanding of the terms, was not able to follow along and understand its overall importance. Once she had the opportunity to do some simple experiments, she began to realize the importance of the research as well as some of the limitations. Her experiences helped her to ask questions and start to see the connections. Specifically, she enjoyed how some of the mechanisms and behaviors studied in animals could easily relate to humans. Through her various experiences, she enjoyed the fact that she had the opportunity to contribute to a discipline that she was interested in.

For Abby, she initially thought she was interested in microbiology which she attributed to her narrow knowledge of the biological sciences at the time. At her community college, microbiology was one of the only hands-on courses available. She said one of the things that made it interesting was when she realized "like 'whoa' this is so cool, there are like other things out there besides your basic biology knowledge." She found the in-depth learning of the material through hands-on experiments fascinating and that had a huge influence on why she thought she wanted to go into microbiology. "I liked doing the work [microbiology], but then it took seeing like other types of work to realize what I wanted to do." When describing the transition period, she said, "I started getting those experiences [in microbiology], and I realized that it wasn't for me, so before I made the jump to conservation, I made sure to get those hands-on experiences." She wanted actually to try it out so that she did not spend too much time working towards this pursuit, only to realize that it wasn't really what she wanted. One of the primary way in 
which she felt she could determine if this what she wanted was through the active use of the concepts.

For Darcy, she realized what she wanted to do early on; noting one of her first memorable ecology experiences was in a biodiversity course set at a local zoo. This hands-on experience occurred early on during her undergraduate career and helped open her eyes to the opportunities available to her. As a child, she had always wanted to be a veterinarian and, until taking this course, she "didn't realize that there were tons of other things that you can do with animals". The class covered interesting ecological and behavioral concepts that she had never had the opportunity to learn about in high school. Darcy then was able to parlay this experience into an internship at the zoo, which helped her obtain other research and environmental education opportunities. In all of her experiences, Darcy touched on a common trend of intellectual stimulation. She enjoyed the process of designing an experiment or program from scratch. It was much more enjoyable for her actually to work with the content rather than just regurgitate what someone else has already done.

Unlike the other three participants, Colin did not describe specific formative experiences. For him, he considered most scientific disciplines as equally interesting for the sheer fact of intellectual stimulation. While perusing his bachelor's degree in biology, he was required to take some supporting science courses like organic chemistry, physics, cell biology, and genetics. When he initially viewed the material and assignments as something that he simply had to do for a course or degree, he was not too interested. However, when he was involved in lab portions of these courses, he realized that he was 
hypothesis testing different concepts. This realization was what then made the material exciting for him, seemingly regardless of the discipline.

Colin believed that one of the reasons he chose ecology, over other seemingly attractive disciplines, was based on his curiosity to question. He mentioned that "I wouldn't be doing what I am doing now if it wasn't for basically [my] inherent curiosity and a sense of wonderment." For him, this curiosity was much stronger when he had the ability to ask his own questions rather than trying to answer those from other people. Entering graduate school seemed to allow Colin the intellectual freedom to pursue his own interests. He believes that had he not had that freedom, he would not have been excited about his job as a scientist.

Faculty/Mentors. Brittany discussed the most about her experience with her research mentors. These mentoring relationships existed with graduate teaching assistants during her animal behavior lab (a very formative course for her), as well as during her undergraduate thesis with the support of her thesis supervisor and a post-doc in the lab. Initially, one of the things that initially helped shape her aspirations for the discipline was that her mentors provided her someone to talk with and ask questions. That supportive environment was further fostered by the willingness of her mentors and advisors to include her in various aspects of the research and providing encouraging remarks towards her work. She developed a close relationship with these mentors and shared with them other factors weighing on her decision. The sense of encouragement she received helped to reinforce her passion for the subject and cemented the idea that she could turn this into a successful in this career. 
Similarly, Darcy also developed a close bond with her faculty mentor. After taking one of his courses, she felt like she developed a great rapport with her undergraduate advisor. Her enjoyment for the class sparked her interest towards his particular research which in turn motivated her to start an independent research project. Once in the lab, she found a strong network of current and former lab members who help build her passion for the discipline. The collaborative nature encouraged her to present at finding at conferences and also gave her confidence in her work. Although she chose to take a job directly after school, the encouragement from her mentor helped show her that she was equipped for graduate work once she eventually decided to return.

Colin stated a similar expression of gratitude for the support and encouragement that he relieved from his different mentors. He felt very fortunate that his undergraduate professors were very accessible. Although there was a limited number of biology courses at his small liberal arts school, he thought that they made an extraordinary effort to be supportive of his personal and academic life. Although not always through formal curriculum, his professors were very active in trying to get their students involved in a wide variety of extracurricular activities. This support helped him navigate the new and seemingly tricky world of higher education. He felt that the openness of his mentors helped open doors and shaped what direction he thought he could take for a career.

Unlike the other three participants, Abby's mentor experience was not within the discipline that she ultimately decided to follow. During both her associate degree and the first few years of her bachelor's degree, her mentors were focused on microbiology. In both locations, they recognized her ability in the field and encouraged her to pursue microbiology. However, she felt like there was continued pressure to stay the course after 
she realized that she wanted to make a last minute switch to ecology. Abby credits the diversity of research interests within her large four-year institution to exposing her to the subject and providing some people to seek out to weigh her decisions. Had she not been able to find so many people, Abby does not think that she would have had the confidence to pursue ecology at such a late stage. It was critical to speak with professors and other professionals for her to realize what the discipline was actually about. She said, "I think [talking with professors] really had a huge impact on me like there is so much to do within the conservation world." This interaction seemed to have a greater impact than that of her microbiology professors in that they encouraged her to follow her interests.

Seeing Themselves Following Their Mentor's Footsteps. For Abby, although she had initially chosen to pursue microbiology, conservation was something that she had always been drawn to. However it took an ecology course and a few hands-on experiences for her to realize, "wait, I really can have a career in this." She did a field experience with one of her professors, and that was it clicked that this could be a career for her. Although she did not describe how that transformative moment came about, she did note that some of the reasons for not coming to this realization earlier were likely due to external pressures from family, friends, and professors.

Where these pressures seemed to limit Abby, Brittany was able to find her interests by following along in the footsteps of her mentors. This began by simply applying their previously successful experimental designs and procedures towards answering her own research questions. This eventually led her to the realization that she could take her passion for animal behavior and turn it into a career. Although she did not want to follow the exact path as either of her mentors, she saw how different aspects of 
their career could apply to where she wanted to go. It provided her with a solid base and some direction. It seemed to be the proper amount of encouragement and exposure to the material to help her start to find her career direction.

Although Colin also had similar experiences as an undergraduate, it took until he entered graduate school for him to envision himself in this career. He felt that his curiosity could only get him so far, and he needed the experience of actually doing real research to see if he was actually "cut out for that particular option or that particular direction." Looking back, Colin believes that his experiences, although not always along the same track, were crucial building blocks that helped him realize that he was good at this and that he could make this his career.

Like Colin, Darcy also had a similar attitude towards how her experiences shaped her career path. She believed that at least some part of all her notable experiences had helped her decide what she wants to do with her career. Her experience with the zoo showed her that there were many opportunities available within biology and ecology. Then through working in government and educational programs, she feels like these experiences have help cement that this is the type of work that she wants to do for the rest of her life. However, almost more importantly, these experiences showed her the kind of things she does not want to do as a full-time career. Although she enjoyed the educator and technician type jobs, she has realized that she wants more say in what she is working on. She thinks that she will likely achieve this once she has completed her Master's degree and can assume a more managerial role. 


\section{How Have Other Types of Experiences Shaped Their Career Aspirations?}

School Choice. For many of the participants, the opportunities available to them at their schools influenced where and when they made their decisions about career and discipline choice. Many of them reflected upon how they chose their particular college or program any the positive and negative influences that those decisions had. Although many students discuss this regarding the presence or absence of specific hands-on opportunities, school choice was classified under this category since the possibilities are a result of their decision rather than a cause.

Abby was the first to note how her education, in particular, shaped the progression of her interests. She felt like she did not have a very challenging high school education which was then one of the reasons she mentioned that she began a dual enrollment program at a local community college. She felt her curriculum was very basic and that "there was nothing that you could get out and explore." Abby both excelled in and enjoyed her three high school biology and this seemed like a logical progression to continue within community college. Although she did not mention whether or not they specifically influenced her decision to study biology, she said that they did impact her path to higher education.

One of Abby's first big decisions was choosing to earn her associate's degree at a local community college after taking a years' worth of dual enrollment credits during high school. When discussing the educational advantages, she acknowledged that this provided significant academic benefits to her during high school, but state that she felt like it may have put her at a disadvantage when trying to determine her career path. Her parents strongly pressured this decision to attend the community college for a 
combination familiarity and financial reasons. Both her mother and her older brother earned their associates a local community college followed by attending the same exact four-year institution to complete their bachelors'. Abby sarcastically described the mentality behind this decision as "cause if it worked for them, it must work for you". She also mentioned that there were monetary factors, such as a full scholarship, that drove this decision. "I mean, if you have the option to get a year of college free, and not have to pay for living as opposed to going to an expensive college and paying to live, parents see that as a win."

Although she understood and could appreciate her parent's reasoning, she would have preferred to attend a four-year institution from the very beginning. She felt that the small community college was not able to provide her with the variety of opportunities needed to help her determine her career path. She was limited by the number of laboratory courses offered and was not exposed to the range of disciplines available at most four-year institutions. Since this was the only thing she knew, she got heavily invested in microbiology and continued in this direction after transferring to a larger school to pursue her bachelor's degree. She felt so focused to get through to a degree that she missed out on a lot of opportunities to experience what was available in biology.

During her final year at perusing her bachelor's degree Abby was finally exposed to an introductory ecology course and ultimately decided to switch directions towards conservation. Had she been exposed to ecology earlier on in her collegiate career, Abby was confident that she would not have gone into microbiology. Although appreciative of the microbiology experience, she felt like it held her back from developing the credentials she needs to succeed in conservation. These are now gaps that she is starting to fill while 
a graduate student. While a little more challenging, she still believes that she will be able to obtain these skills and her decision to choose microbiology will not prevent her from achieving a career in conservation. However, given the opportunity to do it again, she would want to skip the associates' degree and spend four years at a more traditional institution in hopes of being exposed to ecology earlier on.

While not to the same extent as Abby, Colin also felt limited by his undergraduate school choice and this was something that he and his brother had recently discussed in length. Only a few years apart, they were first in their family to attend college let alone graduate school. Colin acknowledged that as a teenager, he did not know what to look for in a college. The two primary reasons he chose to go where he did was the low student to faculty ratio and the fact that his brother was also attending. Although he credits these two reasons for helping him navigate through the challenges of higher education, he and his brother constantly wonder where they may be had they gone to a more research intensive institution. For Colin, the structure of that liberal arts education did not emphasize faculty-driven research as much as he may have hoped. He saw how formative his research experiences were for him as a graduate student and could only imagine where he might be today had he had access to stronger research programs. Unlike Abby, Colin does not think he would choose another institution, but he does also wonder how much further he might be in his career had he had access to a wider range of opportunities. He tried to make it clear that his reflections of these experiences were not necessarily "looking back longingly or with regret, but it's just an acknowledgment".

For Brittany, she wished that her high school could have done more to help focus her career directions. Although she felt that she received a quality education, when it 
came time to make a decision about careers she would have liked to see more information about the realities of medicine. Everyone seemed to encourage these high profile careers but no one ever actually mentioned the need to "consider a plan b." The difficulty of coursework, high (almost unobtainable) expectations, and other educational interests were all reasons why Brittany stressed that it was important to consider a backup plan. When she finally realized that she no longer wanted to pursue a career in medicine, she felt scared and uncertain because she had not thought of other possibilities.

However, unlike both Abby and Colin, Brittany thought that there were a sufficient number of opportunities available to her at the large research institution. Through different degree requirements, she took a combination of courses that allowed her to explore and branch out in the directions that most interested her. She also noted that since she was in her school's honors program, it opened up additional opportunities for her. It required her to take an extra laboratory course and as well as complete her undergraduate thesis project. These two experiences turned out to be extremely beneficial and drove her career aspiration. However, Brittany said that without the requirements imposed on her by the honors program, she didn't think that she would have sought them out on her own.

Family Support. Family had played a major role for all four participants. However only Abby, Brittany, and Colin specifically described how their family felt about their particular discipline decisions. This seemingly unconditional support helps to boost the student's confidence in the discipline. However, unlike faculty mentors, their families were not well versed in navigating a career in science. Although parents may have 
provided emotional support, it did not appear they were able to open up any new opportunities specifically with the sciences.

Although Abby felt that her parent's pressure to attend community college may have limited her career opportunities, they were very supportive of her choice of majors. This was particularly true for microbiology. Her parents saw microbiology as a very stable and lucrative career that she would enjoy. Abby noted that this quick validation for microbiology may have prevented her to consider a backup plan and caused her not to seek out other opportunities disciplines. However, when she decided to switch to conservation, her parents (specifically her mother) were very supportive. Although they were initially hesitant to such a big change so late in her degree program, they were able to see that she was passionate about the subject. Although Abby did not specifically make the connection, her decision to seek out the advice of professors and other professionals during the transition likely made it easier for them to support her decision.

Brittany's family show similar support to her decision to pursue a path in animal behavior rather than medicine. Although her mother has been unconditionally supportive of her career decisions, she noted that her father was initially against the idea of her switching. "I had been talking to him about being a doctor since I was like seven so this was a big deal." However, once she was able to show him that she actually enjoyed the field and that it could support her financially, he started to open up to the idea. Her siblings showed similar skepticism towards to her decisions primarily because they did not understand her desires to work with birds and described it as weird. Similar to Abby's parents, Brittany felt that her parent's reservations were with how the change may affect the progression for her degree as opposed to her ability to succeed at what she was doing. 
Colin also felt strong parental support for his decision to pursue science. He never felt like he was forced to seek anything that he did not want to pursue. He acknowledged that his parents were not well versed in navigating higher education, let alone biology, and regardless of their knowledge they were very supportive of his choices throughout the entire process. Colin did, however, mention that his brother was very helpful in showing him the ropes during the two years they were both at the same institution. This support was primarily in the form of how to succeed as a college student, as opposed to tutoring or career advice, and "was probably the best environment that [he] could have been in". The idea of family support, specifically from his brother, seemed to have a more direct influence than that of Abby or Brittany. For the first two years of college, he had a direct resource at school who he knew he could turn to if he had questions or ran into trouble.

Cultural Support. Brittany was the only participant to mention a distinct cultural influence on her career decisions. She said this rose from a strong cultural tendency within her ethnic community to push their children towards high profile professional degrees. Within that minority community, if a child expressed interest towards one of those professions "they will do anything they can to encourage it because they think 'it's a great idea!.." However, she did not feel as heavy of a cultural burden compared to other kids since she felt like she had a genuine interest in the field. She had many family friends who were in the field of medicine and had encouraged her to follow her desires. Had she expressed the wish to pursue a lower profile career, she thinks that there may have been more pressure to switch. However, she felt that her parents held a more progressive perspective within the community and would have viewed a desire towards 
less prestigious fields as a waste of talent. She mentioned that parents in general still "love to say that their kid is a doctor or a lawyer", but the more recent opinion is that there are now other things that their children can do to achieve a successful and financially stable career. It was this view that she believed allowed her family to accept her decision to pursue animal behavior rather than medicine.

Work/life Balance. When discussing other influence on her career decision, Darcy was very emphatic about the importance of a healthy work/life balance in her career. This seemed to weigh very heavily on her mind and was one of the only things she discussed outside of her academic experiences. For her, the work/life balance had two personal priorities: starting a family with her husband and being within close proximity to her parents and extended family.

Darcy is hesitant to pursue a $\mathrm{PhD}$ at the moment in order to have kids. She said, "I know it's doable, and I know plenty of people who do it, but I just don't think it's just what I would really want at this point." She feels like the pressures of academia, especially in the sciences, would require her to devote over 60 hours a week to her research; time much rather spent with her family. Eventually, she may see herself returning for a $\mathrm{PhD}$, but at this point, she is pretty set in her decision. Although she has discussed this with other graduate students and young professionals, Darcy wished that she had greater mentorship from faculty on how to balance a successful academic career with a family.

Since she has decided to forgo a $\mathrm{PhD}$ at this time, Darcy has thought about her options within the workplace. Her ideal job would allow her to move back to her home state, if not her home city so that she can raise her family close to her parents. For her, 
"being closer to my family at this point kind of outweighs that dream job". She acknowledges that she may need to search a little longer or take something that is not ideal, but that the sacrifices would be worth it. However, she still feels confident that, with her skills and education, she will be able to find a position that she would enjoy.

Outdoor Interests. Three out of the four participants mentioned that outdoor experiences as a youth helped shape their overall career aspirations. Although they did not cite this as a driving force, two participants elaborated on how this helped shape their interests and curiosities.

For Abby, she mentioned growing up on a farm and living an active outdoor lifestyle. "[Her] family was really active, going on trips, going on trails, canoeing..." which is also why she thinks she prefers a conservation profession that involves fieldwork, rather than being stuck in a microbiology lab. She also mentioned a genuine love for animals which helps drive her to want to protect and promote endangered populations. "There are just many things that, when they all come together, that you realize that you've been doing all your life and that you love and that they can be meshed into a career."

Colin also had expressed that he had developed a deep appreciation for the outdoors at a very young age. This was fostered by spending time with his dad and brothers "hiking in the woods, fishing, and just participating in various outdoor activities". While he did not interpret what he saw as a boy from an ecological or evolutionary perspective, these activities help spark his curiosity in the world around him. He thinks that this appreciation for the outdoors is what helps allow him to appreciate the time he spends doing fieldwork. However, Colin makes an important distinction that his 
questions about ecological processes in natural populations are what drive the need for fieldwork rather than only a desire to do fieldwork. Although he is thrilled to conduct field experiments, he is just as happy in the lab so long as he is still actively involved in the scientific method.

\section{How Do Their Aspirations Fit Into the Framework of Self-Determination Theory?}

During their interviews, all four participants displayed varying levels support towards the three basic psychological needs outlined by self-determination theory: competence, autonomy, and relatedness. At certain points, not all three of these needs have been fully met, and their aspirations seemed to reflect the level of their internal and external motivators. As a general trend, competence appeared to increase over time and with that confidence that they were perusing the correct discipline or career decision. Similarly, as participants began getting hands-on experiences, their enjoyment also seemed to increase within the discipline. This is likely correlated with the sense of autonomy to conduct their projects or research. Although autonomy did not always increase with experience, their enjoyment increases with autonomy. Relatedness varied a little. However, there was an overwhelming sense of support from family members towards whatever path they eventually chose.

Abby. Abby began her collegiate career with some very controlled motivators, however as she progress through she was able to shed some of those motivators and greater support her three basic needs. Her decision to pursue her associate's degree appeared to have substantial external regulation by her parents. Between her desire to comply with her parents' wishes and the financial incentives provided by the college, she ultimately chose to go to community college rather than a four-year institution. Although 
this decision did not seem to influence her choice towards the biological sciences, she did feel that it limited her in the exposure that she had towards focusing on a particular discipline. Given the ability to do it all over, she believed that going to a larger research school from the beginning would have opened her up to her passion for ecology much sooner, and she would feel better equipped (higher competence level) for her career direction.

Both ecology and microbiology had clear autonomous motivators from Abby. She seemed like she genuinely enjoyed both, however when discussing a career in microbiology, her aspirations and goals were not as clear. Although she was not necessarily clear with her goal in ecology either, her reasons were much more articulate and internalized.

Although she felt a high level of competence with the material, Abby felt pressures for her to stay in the microbiology from both her parents and her professors. She cited that some of these pressures were likely financially driven since there is more money in microbiology. Others, and possibly even herself, wanted her to be well off and saw microbiology as a way of achieving that goal. When bringing up the switch to ecology with one of her microbiology professors, he strongly encouraged her to stick with it. She wasn't sure the exact motives behind why he encouraged her to stick with it rather than following her passions. However, regardless of the reasons, she was eventually she was able to break free of these pressures and pursue a path in conservation. Although this interview did not examine how she was able to break these constraints, she did say that “micro wasn't really where I wanted to be... it didn't really 
fit my personality as well, I'm just not a person that wants to be in a lab all day 24/7, I really like being outside"; a prominent sign of autonomous motivation.

Being new to the conservation discipline, Abby is feeling slightly lower levels of competence. However, her drive towards conservation exhibits much more autonomy than described with microbiology. Abby has also taken steps towards supporting her need for relatedness. In her interview, she said "I think that I just made the effort to get out of the micro[biology] opinion and I went and talked to a lot of people... they really encouraged me that it's so doable". By seeking out the opinions of respected professionals within the field, she was looking to validate her decision. Since then, she has been actively seeking new challenges and opportunities with the field to increase both her competence and ultimately autonomy. Although initially her family was originally hesitant towards this switch, now that they can see her passion towards ecology and they have been much more supportive.

Brittany. As a child, Brittany had believed that she wanted to go into medicine and be a doctor. Although she considered this decision to be autonomously motivated, this choice of profession was one that was heavily endorsed by her cultural values. Her family and those within her community saw that she indicated a desire for this and tried to help foster it. Although the culture may have planted this decision, it was one that Brittany embraced through identified regulation.

Once Brittany entered her undergraduate career, she found out that she did not want to pursue medicine and which seemingly lowered her level of competence. Although she felt a little pressure from her parents, specifically her dad, to stick with it she decided to follow her interests and switch to the biology/psychology program. By her 
third year, she eventually found that she had an interest in animal behavior. And in her final year, she decided to do her undergraduate thesis in animal behavior. During her interview, she stated: "I was lucky that the research portion of the thesis was mandatory for me because I don't know if I would have sought it myself." Even though she had an interest in the field, her choice to pursue these opportunities was driven by necessity to complete her honors degree program and exhibited strong introjected regulation. This project, along with other class related ones helped boost her competence in the field and helped drive her to pursue a graduate degree in animal behavior. Throughout this process, she was able to meet her need for relatedness by showing her parents that this could provide her a successful career that she would enjoy. This was likely a result of her succeeding in her research projects, which helped meet her needs of competence and autonomy, and reaching a high level of identified regulation.

Darcy. When describing her full range of experiences, it seemed clear that each one helped build her level of competence towards ecology. Darcy appears to have felt the highest degree of relatedness during her undergraduate research. There was an amazing culture created by the group of current and former lab members which encouraged her to participate in science and follow her interests. However, during experiences outside of academia, such as with the government position as well as her educational role, she felt very limited when it came to autonomy. She did not feel like she had a voice and felt forced to follow the procedures set by her supervisors. Her sense of competence further impacted this restrictive feeling towards what she was researching. Darcy felt like she had the knowledge to make improvements but did not feel like she had the chance to be heard by superiors. 
This lack of autonomy in the workplace was just one of the primary drivers towards coming to grad school. While a higher degree would likely provide her with more autonomy in the workplace, it would also open up more career opportunities. Although the increased number of opportunities can lead to a more successful career, Darcy also saw this as an opportunity to pursue other aspirations such as start a family. For her, relatedness took on a slightly different form as it drove her to seek a reasonable work/life balance rather than "traditional career success". Her ability to break some cultural norms of success within the sciences displays a high of integrated regulation.

Colin. Colin's need for relatedness seemed to support his career aspirations from an early stage as he mentioned that he had always felt encouragement and support for whatever path he chose. Similarly, he developed a sense of autonomy at a young age that grew as he progressed through his education. As a child, he had always had a curiosity for nature and was encouraged to seek out his curiosities. This autonomy eventually felt restricted in some of his undergraduate experiences where he felt interjected regulators pressuring him to complete assignments. However he noted, "When I realized what I was actually doing was testing hypothesis experimentally, that actually became really exciting." He took these required activities, internalized their importance and was truly able to gain enjoyment out of them, thus displaying integrated regulation.

It was not until graduate school when Colin felt like he was consistently able to support high levels of autonomy and competence. Although he did not give examples of specific experiences, he was able to describe how working with intrinsically regulated and extrinsically regulated questions sparks his interest in a topic: 
"Well, I'm a hell of a lot more interested in my own questions than other people's questions. And that I think, you know, is an important step. I mean before we can ask our own questions and answer those questions, we need some experience in terms of figuring out how to answer questions in general. And in that sense, at a very early stage in our education and our experiences that, basically being given a question that might not be our own, is pretty important. Even if it is not something that we are deeply passionate about doing, it is an important step in learning how to basically answer a question that has been asked. Whether by us or by anyone else. And although that might not be as intellectually stimulating, I think it's an important step. But when I entered graduate school and started asking questions of my own, and realizing that I had the intellectual freedom to be able to do that, it was really exciting. And that's what basically made me excited about being a scientist. It's getting up every day and being excited about answering questions that interest me."

Colin sees these controlled motivators as stepping stones towards an ultimate goal of intrinsic regulation. Although he was able to heavily internalize the concepts presented to him as an undergraduate, he did not feel like he ability for genuine autonomy until he reached further into graduate study. Between this and the constant sense of support towards following his passions, Colin was able to display the clearest sense of intrinsic motivation. 


\section{Discussion}

How Have Experiential Learning Opportunities Shaped Their Career Aspirations?

Regarding how experiential learning developed career aspirations, three themes emerged: Enjoyment of the discipline, faculty mentorship, and their ability to identify with a career. Interest for the discipline was the most significant. Their interests led to opportunities to work with faculty on hands-on projects. Encouragement and interest enabled these participants to determine their career direction.

Participants found that their interests were encouraged and honed due to the support of faculty and other influential mentors. These mentorships provided students with someone that they could seek out and ask questions. Although primarily academic related, participants noted a close relationship with their mentors that extended outside academia. The extra support was minor and involved personal and career advice. However, small gestures helped students shed ideas and pressures that might have prevented them from perusing a career in science.

Participants often cited the combination of interest for the subject and the encouragement that they received from mentors as contributing to them being able to see themselves with a career in science. For some, following in the footsteps of someone more experienced help them establish their direction while others found this limiting. However, the participants felt like they were able to learn from both positive and slightly negative parts of their experience. These experiences gave them a personal connection to reflect upon and helped allow them to see if they were on the right path. 


\section{How Have Other Types of Experiences Shaped Their Career Aspirations?}

One of the most discussed topics was the number of available opportunities (or lack thereof) at their chosen college/university. Two participants felt limited by the type of institution that they attended and had wondered what it would be like if they had gone to a more research intensive school from the start. In this light, these students found their decision to be detrimental to the progress of their career. Although the value of an educational setting was not thoroughly examined by the design of the research questions, it was a theme that emerged through many of the participants. Brittany's narrative speaks to the speculative nature of this point. She went to a large research institution, and although she did find her discipline by exploring the broad range of courses available at her institution, she admits that she would not have done so if not compelled to by her honors program. Her remarks helped demonstrate that the availability of world-class opportunities does not necessarily translate into students taking advantage of what is available to them. Conversely, other participants demonstrated an ability to succeed in science with much more limited resources and opportunities. However, there was a consensus among the participants that additional opportunities certainly advantageous and may ultimately increase the speed and likelihood of reaching their aspirations within science.

Family and cultural support were essential for validating the student's desired career path. Although participants felt an unconditional support from their parents towards their decisions, they acknowledged that they were fortunate to have this type of support network. Brittany's narrative about her cultural influences showed how a student could be easily pressured towards a high profile and financially rewarding career, rather 
than one in which they had a genuine interest, and this impacted her decisions. Her parent's decision for her to attend community college rather than a four-year college prevented her from experiencing ecology disciplines widely available at larger institutions. Parents' genuine concerns with the happiness and wellbeing of students seemed to produce unintended and counterproductive consequences. This was found to be particularly true for Abby and Colin, whose parents had limited understanding of higher education in STEM fields. Although parental support did produce some minor setbacks for these participants, their overall openness and acceptance of the student's desires enabled their success in science.

Related to career validation was a desire to seek a healthy work-life balance. Surprisingly, this factor was only mentioned by one participant. Darcy said two personal priorities that outweighed her aspirations for an ideal career: starting a family and being close in proximity to her parents and extended family. Although she knew successful scientists who have achieved a reasonable work/life balance, she would rather focus on her family. Darcy felt that her skills and education provided more freedom to pursue family goals. Darcy was confident that she will find a position that will support her family as well as continue to advance her career.

\section{How Does SDT Explain Their Aspirations?}

The final research question used self-determination theory to evaluate their career aspirations. By determining how their experiences met the three basic psychological needs (competence, autonomy, and relatedness), we were able to see what regulators drive motivations. Although these needs were variable within and among participants, there was a trend towards higher internalization of motivators and intrinsic aspirations. 
For all participants, competence increased as they progressed further in their discipline. Hands-on experiences provided them a sense of validation. Participants built on their classroom knowledge and demonstrated application of theory by conducting research. Participants exhibited a greater and faster sense of growth in their perceived competence while doing independent research. This was likely due to these projects requiring students to draw upon a range of interdisciplinary knowledge and skills and the increased sense of autonomy.

Although competence and autonomy increased, both Darcy and Abby expressed instances in which low levels of autonomy altered career aspirations. Darcy expressed frustration towards her supervisors due to lack of input she has in implementing research protocols. For her to obtain the level of autonomy she desired, she realized she would need to continue her education if she were to remain in science. Unlike Darcy, Abby's limited sense of autonomy manifested due to a heavily externalized career in microbiology. Strong pressure by her parents and research advisors caused her to believe that she should persist in that direction. What seemed like the helpful encouragement of Abby's persistence in microbiology, these external pressures ultimately limited her from exploring aspects of biology, such as ecology, in which she could more fully express her passions. Only once she was able to shed these external pressures was she able to build her sense of autonomy.

Overall, as participants began to build support for autonomy and competence, their levels of relatedness also increased. While everyone appeared to have a very supportive network of friends and family, they still exhibited an internal desire to be successful. Through success during hands-on opportunities, they built genuine interest 
and experienced a high level of competence. This has been particularly true for Abby and Brittany, who chose to switch disciplines. During this transition, parents had a genuine concern about them choosing an appropriate career direction. For these participants, their hands-on experiences helped establish confidence regarding a career path. For all participants, once they were able to determine a career path and satisfy all three basic needs, they were able to display clear intrinsic aspirations. Although many of the participants still exhibited some form of external motivation, the underlying factor was a strong internalization of their desires. From there, their career aspirations were almost always driven out of an apparent enjoyment for their chosen discipline.

\section{Implications}

Due to the targeted recruitment, all participants expressed interest towards ecologically related disciplines; however their views of this discipline along with their aspirations within that field varied. Sauvé (2005) notes different environmental perspectives and aims and approaches to solving issues consistent with those of our participants. Although specific perspectives were not examined in this study, it is an important component to helping students identify with any STEM field (Hill et al., 2010).

As participants began engaging in more complex research, they developed a genuine enjoyment and appreciation for the discipline. This involvement is extremely beneficial for students to identify themselves as scientists (Gazley et al., 2014; Hill et al., 2010), especially when coupled with mentors who validate their progress and provide a model for career aspirations. Gazley et al. (2014) suggest research mentorship, especially for underrepresented students, contributes beyond scientific preparation also to how students create a scientific identity in relation to their cultural capital. For the participants 
of this study, the more experiences they were able to obtain, the clearer picture of how they saw themselves as an ecological scientist.

Although experiential learning opportunities had a clear impact on participant's career aspirations, there were also other factors that were important for these participants. These included themes like college choice, family and cultural support, work/life balance, and outdoor interests. Although not as clearly related to specific career aspirations, these seem to influence how their three basic psychological needs of SDT were met. These aspects of the participant's lives all had varying levels of intrinsic and extrinsic motivators which regulated their aspirations. SDT suggests that as levels of autonomy, competence, and relatedness increase, so does the intrinsic nature of their aspirations (Deci \& Ryan, 2000, 2008; Vansteenkiste \& Ryan, 2013). Such was the trend seen throughout all of the participants. The involvement in these hands-on learning experiences seemed to help shed extrinsic regulators by developing a greater sense of competence and autonomy. The increase of these two needs also appears to strengthen the support of friends, family and mentors who saw that the students had genuinely internalized their desires for the discipline and would likely succeed in a STEM career.

For many of our participants, experiential learning experiences early within their undergraduate career allowed them to take an "interest testing" approach (Gazley et al., 2014). When students were able to relate these experiences to something outside a course requirement, they saw the connectivity of the subject and could relate it to their aspirations as a scientist. By providing students links to a seemingly arbitrary discipline, it helps increase their scientific ability as well as develop a truer sense of what is expected within a discipline (Gazley et al., 2014). This may help retain students within 
particular disciplines and direct students to explore other possibilities earlier within their academic career. This extra exposure to hands-on experiences can help students find confidence and success, which in turn will help to promote their STEM identity. This sense of confidence and belonging can also help shed any doubts or external pressures that may make students believe they cannot achieve or do not belong in science (Kusurkar et al., 2011).

By gaining a better understanding of how the student's experiences influence career decisions, it is possible to make recommendations towards how science is expressed at the undergraduate level and hopefully enable more students to reach their potential in STEM disciplines (Hill et al., 2010). Though this reflective study, selfdetermination theory has been shown to be an applicable lens for which to examine undergraduate research experiences. The semi-structured interviews provided an exhaustive look into participant experiences, however, this time consuming process would be difficult to scale this method for widespread evaluation of scientific research programs. The broad themes that emerged through this process can be used in the development or more efficient and transferable quantitative surveys. While there are currently no instruments that can evaluate all of these different domains, SDT literature is rich with validated instruments that may be able to be combined to help explain student's motivation towards these hands-on experiences. Doing so would help provide faculty and program coordinators, who may be unfamiliar with much of the scientific education literature, to meaningfully evaluate their programs. 


\section{Acknowledgments}

This project was approved and monitored by the Illinois State University

Institutional Review Board: IRB \# 2009-0373. I would also like to thank Wendy Troxel

for her guidance and revisions during this pilot study.

\section{References}

Boettcher, T. (2014). Forging partnerships with education to solve the skills gap. Techniques: Connecting Education \& Careers, 89(1), 32.

Brown, C. J., Hansen-Brown, L. J., \& Conte, R. (2011). Engaging millennial college-age science and engineering students through experiential learning communities. Journal of Applied Global Research, 4(10), 41-58.

Buckley, J. A. (2010). Undergraduate research experiences. (Doctor of Philosophy), Indiana University. (3439283)

Caudle, S. L. (2004). Qualitative data analysis. In J. S. Wholey, H. P. Hatry \& K. E. Newcomer (Eds.), Handbook of practical program evaluation (2nd ed., pp. 417438). San Francisco: Jossey-Bass.

Dana, N. F., Dana, T. M., Kelsay, K. L., Thomas, D., \& Tippins, D. J. (1992). Qualitative interviewing and the art of questioning: Promises, possibilities, problems, and pitfalls. Paper presented at the Qualitative Research in Education Conference, Athens, GA.

Deci, E. L., \& Ryan, R. M. (2000). Self-Determination Theory and the facilitation of intrinsic motivation, social development, and well-being. American Psychologist, 55(1), 68-78. doi: 10.1037110003-066X.55.1.68

Deci, E. L., \& Ryan, R. M. (2008). Self-Determination Theory: A macrotheory of human motivation, development, and health. Canadian Psychology, 49(3), 182-185. doi: $10.1037 / \mathrm{a} 0012801$ 
Fechheimer, M., Webber, K., \& Kleiber, P. B. (2011). How well do undergraduate research programs promote engagement and success of students? Cell Biology Education, 10, 156-163.

Gazley, J. L., Remich, R., Naffziger-Hirsch, M. E., Keller, J., Campbell, P. B., \& McGee, R. (2014). Beyond preparation: Identity, cultural capital, and readiness for graduate school in the biomedical sciences. Journal Of Research In Science Teaching, 51(8), 1021-1048.

Guest, G., Bunce, A., \& Johnson, L. (2006). How many interviews are enough? An experiment with data saturation and variability. Field Methods, 18(1), 59-82.

Heddy, B. C., \& Sinatra, G. M. (2013). Transforming misconceptions: Using transformative experience to promote positive affect and conceptual change in students learning about biological evolution. Science Education, 97(5), 723-744. doi: $10.1002 /$ sce. 21072

Hill, C., Corbett, C., \& St. Rose, A. (2010). Why so few? Women in science, technology, engineering, and mathematics. Washington, DC: American Association of University Women.

Korkmaz, A., Cole, J. S., \& Buckley, J. A. (2011). Undergraduate research experience: Intention and doing for STEM majors. Paper presented at the American Educational Research Association, New Orleans, LA.

Kusurkar, R. A., Croiset, G., \& Cate, T. J. T. (2011). Twelve tips to stimulate intrinsic motivation in students through autonomy-supportive classroom teaching derived from Self-Determination Theory. Medical Teacher, 33, 978-982. doi: $10.3109 / 0142159$ X.2011.599896

Mackenzie, S. H., Son, J. S., \& Hollenhorst, S. (2014). Unifying psychology and experiential education: toward an integrated understanding of why it works. Journal of Experiential Education, 37(1), 75 -88. doi: $10.1177 / 1053825913518894$

Merriam, S. B. (2009). Qualitative research: A guide to design and implementation. San Francisco, CA: Jossey Bass. 
Oguz, A. (2013). Developing a scale for learner autonomy support. Educational Sciences: Theory \& Practice, 13(4), 2187-2194.

Rothwell, J. (2013). The hidden STEM economy. Washington, D.C.: Metropolitan Policy Program at Brookings.

Sauvé, L. (2005). Currents in environmental education: Mapping a complex and evolving pedagogical field. Canadian Journal of Environmental Education, 10, 11-37.

Sian, G. (2013). Early career change among millennial US college graduates: Chicago, Illinois : DePaul University, 2013.

Strauss, A. L., \& Corbin, J. M. (1998). Open coding: Definition of terms Basics of qualitative research: Techniques and procedures for developing grounded theory (2nd ed.). Thousand Oaks: Sage.

Tabachnick, S. E., Miller, R. B., \& Relyea, G. E. (2008). The relationships amoung students' future-oriented goals and subgoals, perceived task instrumentality, and task-oriented self-regulation strategies in an academic environment. Journal of Educational Psychology, 100(3), 629-642. doi: 10.1037/0022-0663.100.3.629

Vansteenkiste, M., \& Ryan, R. M. (2013). On psychological growth and vulnerability: Basic psychological need satisfaction and need frustration as a unifying principle. Journal of Psychotherapy Integration, 23(3), 263-280. doi: 10.1037/a0032359

Vlachopoulos, S. P., Kaperoni, M., \& Moustaka, F. C. (2011). The relationship of selfdetermination theory variables to exercise identity. Psychology of Sport and Exercise, 12(3), 265-272. doi: http://dx.doi.org/10.1016/j.psychsport.2010.11.006

Wang, M.-T., \& Degol, J. (2013). Motivational pathways to STEM career choices: Using expectancy-value perspective to understand individual and gender differences in STEM fields. Developmental Review, 33(4), 304-340. doi:

http://dx.doi.org/10.1016/j.dr.2013.08.001

Wang, M.-T., \& Eccles, J. S. (2013). School context, achievement motivation, and academic engagement: A longitudinal study of school engagement using a multidimensional perspective. Learning and Instruction, 28(0), 12-23. doi: http://dx.doi.org/10.1016/j.learninstruc.2013.04.002 


\section{CHAPTER II}

\section{EXAMINING THE MOTIVATION OF STUDENTS INVOLVED IN}

\section{BIOLOGICAL RESEARCH PROGRAMS}

\section{INTRODUCTION}

Undergraduate research experiences (UREs) often provide students with their first real experience in scientific research. Many leading scientific funding agencies such the National Science Foundation (NSF), Howard Hughes Medical Institute (HHMI) and the National Academy of Sciences (NAS), recognize their importance and have sought to increase STEM retention in a number of scientific disciplines through the support of various undergraduate research initiatives (Harsh et al. 2011; Lopatto 2004). In the biological sciences, common UREs range from course based experience (Maw et al. 2011; Scott et al. 2012), to apprenticeships and independent study (Sadler et al. 2010), to structured summer programs (Lopatto 2004; 2007). These experiences are known to develop a range of transferable skills (Lopatto 2004; 2007) and are particularly useful in promoting the representation of minority students in science (Gazley et al. 2014; Hurtado et al. 2008).

The experiential learning model states that students learn from experience rather than simply through receiving instruction (Kolb 1984). Although there are many different learning preferences, it is a holistic process that revolves around modes of action, reflection, feeling and thinking (Bergsteiner et al. 2010; Kolb 1984). Reflective 
observations of their learning experience enable abstract conceptualization, or when the student can conceptualize the concept, theory or model that they observed during their experience (Kolb 1984). All of these may involve active experimentation, or when students decide how they plan to test the concept further through another experience (Kolb 1984) and does not explicitly require an instructor's guidance (Itin 1999). Experiential education draws upon a number of cognitive-developmental and psychological frameworks such as the theory of well-being, self-determination theory, and flow theory (Mackenzie et al. 2014).

Transformative experiences are activities within science that require the use of specific concepts and result in a meaningful shift of a student's perspective of their everyday life (Pugh et al. 2010). Transformative learning has been used throughout the sciences to help transform student misconceptions by tying complex scientific principles to everyday experiences that they can relate to their personal or cultural beliefs (Heddy and Sinatra 2013; Pugh 2002; Pugh et al. 2010). Such experiences involve active use of a concept, expansion of perception, and experiential value for the concept (Heddy \& Sinatra, 2013). Strong relationships exist between experiential experiences and scientific identity, especially those from underrepresented groups (Gazley et al. 2014). Experiential learning and community involvement build student interest and confidence in STEM fields (Brown et al. 2011). Students who develop research expectations early in their undergraduate career are more likely to participate in these experiences and more likely to persist in undergraduate STEM programs because they are more actively engaged during subsequent years (Korkmaz et al. 2011). 


\section{Theoretical Framework}

The lens that I will be using to understand the relatedness of the participant's development as a scientist is that of Self-Determination Theory (SDT). SDT proposes that the root of motivation is the desire to satisfy three basic psychological needs: autonomy, competence, and relatedness. As a macrotheory in human motivation, it addresses a wide variety of factors that influence growth and well-being (Deci and Ryan 2000a; 2000b; 2008), and therefore it makes sense to view student's career decisions from a holistic approach, as opposed to a reductionist. Deci and Ryan (2000b) state that "different goal contents have different relations to the quality of behavior and mental health, specifically because different regulatory processes and different goal contents are associated with differing degrees of need satisfaction". The goals students experience can result from either intrinsic or extrinsic regulators, both of which vary in the degree to which basic psychological needs are met (Vansteenkiste and Ryan 2013). This study seeks to examine participant motivation during undergraduate research experiences through a spectrum of regulation types:

- $\quad$ Amotivation: An individual lacks any specific intention and is simply going through the motions of an activity (Deci and Ryan 2000a).

- External Regulation: An individual acts in alignment with specific rewards or punishments (Deci and Ryan 2000a).

- Introjected Regulation: An individual begins to accept actions as their own but only as a way to avoid guilt, anxiety or shame. Conversely, this may also be a way in which an individual attempts to demonstrate self-importance. While individuals start exhibiting some internal drivers, this regulation is still driven by 
external pressures and relates to the individual's self-esteem (Deci and Ryan 2000a).

- Identified Requlation: An individual recognizes and accepts the significance of their behavior, and although more internalized, they do not necessarily act out of pure enjoyment or fully integrated personal values (Deci and Ryan 2000a).

- Integrated Regulation: An individual can recognize that they are acting in congruence, awareness, and synthesis with self, even if behaviors are not necessarily inherently enjoyable (Deci and Ryan 2000a).

- Intrinsic Motivation: An individual acts out of self-enjoyment and selfsatisfaction (Deci and Ryan 2000a).

It is also reasonable to believe that the regulation of student's motivation during these research experiences is also influenced by their personal aspirations in life (Kasser and Ryan 1996), as well how their three basic psychological needs are being supported throughout the experience. Self-determined behaviors aid in the attainment of intrinsic aspirations which in turn are positively associated with well-being. As individuals continue to engage in activities that help them realize these intrinsic aspirations, selfdetermined behavior is further supported leading to a recursive model (Deci and Ryan 2000a).

\section{Aim of the Study}

This study seeks to model student perceptions of biological research. In doing so, it will examine three research questions that collectively explore how autonomy, competence, and relatedness are supported during undergraduate research experiences: 
1. What is the relationship between perceptions of biology, motivation during undergraduate research, mentor relationship, personal aspirations and STEM persistence?

2. Does the lens of self-determination theory reflect the nature of undergraduate research experiences within biological disciplines?

3. Does the expression of latent constructs within this relationship differ based on different experience levels?

\section{METHODS}

Survey Construction

The Biological Research Experience Survey (BRES) seeks to understand how the basic psychological needs of self-determination theory are being satisfied during undergraduate research experience. This design of this survey sought to connect previously validated instruments to understand the relationship between the underlying constructs. In addition to five recreated or modified instruments, a number of demographic and descriptive questions were posed in order to understand the nature of their experiences.

\section{Demographic Information}

Since the survey was anonymous, a variety of information was collected in order to understand the background of participants (Tables B2-B4). In addition to traditional demographic information (age, gender, ethnicity, etc.), these questions reveal information about their discipline, prior research activities, and their research mentor. The primary 
purpose is to confirm that the target audience is being reached and understand the representation of meaningful sub-groups.

\section{Motivation Towards Research Experience Scale (MTRES)}

The acquisition of knowledge and skills through undergraduate research experiences is not inherently guaranteed and is likely dependent upon the desire to derive meaning out of the experience. This ability to develop meaning is often dependent upon their perception of autonomy and associated with higher forms of self-determination (Ryan and Connell 1989). To examine how motivation is regulated during these experiences, the MTRES was adapted from the Motivation Towards the Environment Scale (MTES) originally developed by Pelletier et al. (1998) and further validated by Villacorta et al. (2003). The MTES helps illustrate that rather than simply encouraging pro-environmental behavior, a more effective strategy is to foster more self-determined attitudes towards the behavior (Pelletier and Sharp 2008; Pelletier et al. 1998; Villacorta et al. 2003). In this same manner, minimal changes have been made to the MTES that focuses on research experiences. For example, the question prompt "Why are you doing things (e.g. recycling) for the environment?" was adapted to "Why are you engaging in an undergraduate research project?" Similar changes were made to the 26 statements, aiming to keep the emotions the same (pleasure, shame, sensible, etc.) while just changing the context (research project, scientific understanding). These questions (Table A3) are then able to provide measurements of six constructs: Amotivation, external regulation, introjected regulation, identified regulation, integrated regulation, and intrinsic motivation. 


\section{Perceptions of Mentor Scale (POMS)}

During the participant's research experience, the type of regulation they experience may also be influenced by the research culture. The specifics of scientific research culture are variable and involve input from other students, faculty, and research staff. However in this setting, precedents are most likely set and maintained by their direct research supervisor/mentor. To examine this mentor relationship, survey questions were adapted from the Perceptions of Parent Scale (POPS) created by Niemiec et al. (2006). The POPS instrument is a commonly used survey in self-determination theory and with various versions targeting different age classes. The scale that was adapted measures parental autonomy support and control and is geared towards college-age participants. In a similar manner to the MTRES, modifications were made by exchanging mother/father with mentor. Questions on this scale (Table A4) correspond to the perception of three mentor qualities: Involvement, autonomy support, and warmth.

\section{Aspiration Index (AI)}

Wellbeing and the sense of success are often associated with more selfdetermined aspirations (Kasser and Ryan 1996). The aspiration index (AI), developed by Kasser and Ryan (1996), measures seven life aspirations based upon a participant's perceptions of its importance, likelihood of attainment, and progress towards attainment. The AI remained relatively unchanged, but questions about health aspirations were removed to reduce survey fatigue and balance the comparison between intrinsic (growth, relationships, and community) and extrinsic (wealth, fame, image) aspirations (Kasser and Ryan 1996). 


\section{Persistence in Science Scale (PSS)}

To assess participant perceptions of degree aspirations, the PSS was adapted from the aspiration index (AI) developed by Kasser and Ryan (1996). "Life-goal” prompts were modified to reflect five college degrees (associate's, bachelor's, master's, $\mathrm{PhD}$, MD) commonly related to STEM professions and followed the same format: Importance, likelihood, attainment.

\section{Colorado Learning Attitudes About Science Survey for use in Biology (CLASS-Bio)}

The CLASS-Bio survey examines student perceptions about the discipline of biology and was developed by Semsar et al. (2011). This survey was not designed using the SDT framework, however, the advantage of using this instrument is that it places students along a continuum of novice to expert. This continuum aligns with the autonomy supported development of life domains (Soenens and Vansteenkiste 2005) and the regulators of motivation (Pelletier and Sharp 2008; Pelletier et al. 1998; Villacorta et al. 2003). For those reasons, the original scale was deemed applicable and remained unaltered. The CLASS-Bio, along with other CLASS instruments for physics (Adams et al. 2006) and chemistry (Adams et al. 2008), has been rigorously validated and is appropriate for use in a range of undergraduate settings (Semsar et al. 2011).

\section{Participants and Data Collection}

One of the goals of this study was to capture a representative sample of variation that exists among undergraduate students participating in ecology-based research. Recruitment letters for this survey were disseminated through the publically available 
listserv ECOLOG-L three times between September and November 2015. An additional request was also included for faculty and programs directors to ask for a unique survey link so that they could evaluate their individual departments, programs, or courses. Eight program directors/coordinators, responding to the listserv letter, also distributed the survey to their students who were currently involved or recently completed the following types of UREs: Summer internships, an NSF-REU program, independent studies, field methods courses, and an introductory biology course with inquiry-based labs.

Participation in the survey was both voluntarily and anonymous. Individual survey links were active between 4-6 weeks depending on the request of corresponding program liaisons. Participants of the study were compensated through an optional raffle in which one $\$ 100$ gift card was made available.

After deployment, participant responses were checked for completion. Participant responses were removed from for the following reasons: 1) There was a discernable pattern in their responses which would not reflect reasonable response, 2) Identifying questions were not responded to correctly (e.g., press 4 if you are still reading), or 3) Any of the 181 Likert-style questions were omitted. Demographic questions (Table B1-4) were used evaluate that participants were from the correct target population. This also helped to understand the representation of backgrounds and experiences (Figure 1). One hundred twenty-four participants ( $46.26 \%$ of the initial respondents) met these stringent requirements and whose data was able to be used in the subsequent multivariate analyses. 


\section{Data Analysis}

All data manipulation and analyses were done in SAS 9.4 (SAS Institute 2014). Although the instruments utilized in the study had been previously validated, questions forming individual categories were tested for internal consistency using Cronbach's alpha (Table 1). Categories with a standardized $\alpha \geq 0.70$ were considered to be measuring the same single latent construct described in their respective instrument (Santos 1999).

To reveal the underlying latent structure of the five combined instruments, an exploratory factor analysis (EFA) was conducted using PROC FACTOR. The principal axis factoring method was used to account for the shared variance of the 27 constructs measured throughout the survey as well as helping to address the non-normal nature of the data (Fabrigar et al. 1999). A promax rotation (oblique) was performed to account for expected correlations among factors, a reasonable assumption in behavioral studies of this nature (Kline 2013). Finally, to determine the most parsimonious factor pattern, Horn's parallel analysis (Kabacoff 2003) was chosen because it helps take into account variance due to sampling error (Courtney and Gordon 2013). Simulations of this parallel analysis suggested that the first five factors (accounting for $62.19 \%$ of the variance) should be retained, a decision that aligned with the popular, yet more subjective, Cattell's scree test (Courtney and Gordon 2013). Factor loading greater than 0.30 were retained as they illustrated a large effect size for the partial correlations (Cohen 1992).

Using the five factor scores generated by the EFA as dependent variables, a multivariate analysis of variance (MANOVA) was performed using PROCGLM (DiStefano et al. 2009). The categorical predictors were class standing, prior lab research, 
prior field research, plus their interactions. In order to meet the assumption of normality $(\mathrm{W}=0.992, \mathrm{p}=0.710)$, data were made positive (by adding a constant of 5) and then raised to the power of 2. Due to the unbalanced nature of the independent variables, the slightly more conservative Pillai's Trace was used to test the overall effect. Univariate ANOVA follow-up tests, using type III sum of squares, were performed followed by post-hoc Tukey tests were appropriate. To regain power, interaction terms that were not significant were removed from the model during follow-up tests.

\section{RESULTS}

\section{Biological Research Experience Model}

The EFA produced five partially correlated latent variables that help understand the relationship between the 27 constructs measured through our survey (Figure 2). Factor 1 accounted for the largest amount of explained variance (29.62\%) and was positively correlated with Factors 2, 3, and 5. Factor 1 was contributing to all seven categories from the CLASS-BIO survey (enjoyment, strategy, real world connections, conceptual connections, reasoning, synthesis \& applications, and effort), intrinsic aspirations (community, personal growth and relationships), identified regulation and intrinsic motivation. Since these characteristics are positively associated with research scientists, Factor 1 was named Scientific Identity. Factor 2 (explaining 10.02\% of the variance) contributed to mentor involvement, mentor warmth, and mentor autonomy support, and is negatively associated with amotivation and external regulation. It was therefore labeled Mentor Support due to the strong association with all three mentorship variables, the inverse relationship with less desirable motivation regulators, and the 
correlation with Scientific Identity. Factor 3 (explaining 9.06\% of the variance)

contributed to external regulation, introjected regulation, identified regulation, integrated regulation, intrinsic motivation, aspirations towards a $\mathrm{PhD}$, and is correlated with Scientific Identity. For these reasons, Factor 3 was named Research Motivations. Factor 4 is strictly associated with intrinsic (community, personal growth, and relationships) and extrinsic (image, wealth, and fame) aspirations and is not correlated with any other latent variables. Therefore, it was named simply Life Aspirations. Finally, Factor 5 (explaining $6.55 \%$ of the variance) contributed positively to bachelor's degree aspirations, master's degree aspirations, $\mathrm{PhD}$ aspirations, was negatively associated with $\mathrm{MD}$ aspirations and external regulation, and also correlated with scientific identity. These associations led us to name Factor 5 Science Degree Aspirations, accounting for the subtle, yet important, difference between basic scientific research and careers in medicine.

\section{Differences Based Upon Experience Level}

Results of the MANOVA indicated differences in latent constructs, based upon the three predictors of background experience. Using Pillai's trace, there was an overall effect of class standing $\left(\mathrm{V}=0.197, \mathrm{~F}_{10,226}=2.47, \mathrm{p}=0.008\right)$ and prior field research $\left(\mathrm{V}=0.109, \mathrm{~F}_{5,112}=2.75, \mathrm{p}=0.022\right)$, but not for prior lab research $\left(\mathrm{V}=0.028, \mathrm{~F}_{5,112}=0.65\right.$, $\mathrm{p}=0.659)$, the interaction between class standing and field research $\left(\mathrm{V}=0.025, \mathrm{~F}_{5,112}=0.59\right.$, $\mathrm{p}=0.709)$, or the interaction between class standing and lab research $(\mathrm{V}=0.045$, $\left.\mathrm{F}_{10,226}=0.52, \mathrm{p}=0.873\right)$. Further investigation showed that there were significant differences due to class standing $\left(\mathrm{F}_{2,119}=10.38, \mathrm{p}<0.001\right)$ and prior field research $\left(\mathrm{F}_{1,119}=10.59, \mathrm{p}=0.002\right)$ on the transformed score for Science Degree Aspirations (Figure 3b). Specifically, graduate students had higher LSmean scores (33.25 \pm 2.45$)$ than both 
underclassmen (20.36 \pm 2.08$)$ and upperclassmen (24.59 \pm 1.36$)$. Likewise, participants with prior field experience (28.86 \pm 1.37$)$ had had higher LSmean scores for Science Degree Aspirations compared to participants without prior field experience (23.27 \pm 1.91$)$. Similarly, there were significant differences due to class standing $\left(\mathrm{F}_{2,119}=6.74, \mathrm{p}=0.002\right)$ on the transformed score for Mentor Support (Figure 3a). While graduate students had lower LSmean scores (19.67 \pm 2.32$)$ than upperclassmen (27.65 \pm 0.99$)$, neither group illustrated a significant difference compared to underclassmen (23.61 \pm 2.07$)$.

\section{DISCUSSION}

\section{Relationship of Factors}

Not surprisingly, constructs related to scientific identity accounted for the largest amount of variation and correlates with the Mentor Support, Research Motivations, and Science Degree Aspirations. These values characterize the ethos of science (Merton 1968) and have been understood by sociologists for many decades, with Box and Cotgrove (1966) noting that scientists in academia and the public and private sectors value the sense of autonomy, disciplinary communism (peer review and collaboration), and personal commitment to their work. For the majority of the constructs measured, self-determined behavior was aligned with higher scores, an association that continued with positive correlations with many of the latent factors. This relationship helps to reaffirm the applicability of SDT in understanding the manifestation of self-determined behavior in education settings, a process known to promote learning and well-being (Guay et al. 2008; Niemiec and Ryan 2009). 


\section{Alignment of SDT and Student Experiences}

Scientific Identity. The seven domains measured by the CLASS-Bio were all strongly positively correlated with this latent factor. These constructs are useful in understanding participants understanding their attitudes towards biology and about the nature of biology (Semsar et al. 2011). This provides an understanding of participant's progression level in expert-level thinking. Additionally, we see that intrinsic aspirations (community, personal growth, and relationships), intrinsic motivation, and identified regulation are all positively associated with this latent factor. This lends support to the notion that positive scientific attitudes are aligned with the framework of selfdetermination theory.

Research Motivations. With the expectation of amotivation, all regulation types loaded onto the latent factor of Research Motivation. According to self-determination theory, many of the regulators within this spectrum can exist at once (Deci and Ryan 2000b), and we may be seeing these different regulators associated with specific activities within their research experience. For example, tasks such as hypothesis formation or interpretation of results may be intrinsically regulated, whereas menial tasks might be extrinsically regulation. Further investigation of Research Experiences is necessary to understand the particular combination(s) of activities that support selfdetermined behavior and how it interacts with scientific identity. Specifically, participants may be undergoing a transformation in which the experience facilitates progressive shedding of societal or parental pressures in pursuit of more intrinsically motivated desires. Lack of such behavior has been demonstrated to predict high school 
dropout tendencies (Vallerand et al. 1997) and may help explain the positive association with $\mathrm{PhD}$ aspirations. It was also interesting to discover the negative association with relationships and motivation factors. This relationship might be illustrative of the demanding nature of scientific research. The perception of the incompatibility between a sufficient work/life balance may serve as a gatekeeper for many otherwise capable individuals from continuing with scientific research (Gasiewski et al. 2012; Hill et al. 2010). These findings suggest that practical training in developing strategies for attaining work/life balance may lead to greater aspirations toward a PhD

Mentor Support. We see that this latent factor positively correlates with the scores on the POMS and negatively correlates with amotivation and external regulation. This relationship is to be expected as high scores related to mentor interest, warmth, and autonomy support are associated with self-determined behavior and conceptually contrast with externally driven or non-existent motivation. This relationship with motivators places emphasis on the perception of the mentored experience by students in promoting scientific identity. Such a focus may be beneficial when promoting representation of minority students in science (Hurtado et al. 2008). Although little research has been conducted examining the promotion of self-determination by research mentors, there is understanding within educational research that its promotion has an impact on learning gains (Guay et al. 2008; Niemiec and Ryan 2009) but that techniques may vary among educators (Reeve and Halusic 2009; Wehmeyer et al. 2000). Since there are many ways for educators to promote self-determined behavior, further study of the correlation between the mentored research experience and scientific identity may provide insights on 
useful intervention strategies targeted towards students with varying levels of perceptions about the nature of biology.

Life Aspirations. The aspiration index reduced into one latent factor. While positively correlated with all six aspirations, it captures most of the variation from the extrinsic factors. The variation among the intrinsic variables contributes to other factors, notably scientific identity. Since Life Aspirations is not directly correlated with other latent variables, extrinsic aspirations, lack a meaningful relationship to the ethos of the students examined. This indicates that although participants may vary with their extrinsic aspirations, it does not seem to relate to their perceptions about the nature of science or their motivation towards the research experience.

Science Degree Aspirations. The three degrees commonly associated with basic scientific research (BS, MS, and $\mathrm{PhD}$ ) were negatively correlated with external regulation. This is consistent with the benefit of self-determined behaviors. When an individual experiences self-determination toward certain behaviors, he is more likely to continue to perform those behaviors well into the future and even if they become more difficult (Bandura 1977). Our findings suggest that students pursuing the basic science degrees (BS, MS, and $\mathrm{PhD}$ ) have the motivation that will allow them to build a long career as a scientist. In other words, self-determination toward research is likely a necessary component to help to withstand the inevitable negative peer review and grant proposal rejection that all scientists face in their career.

Another interesting relationship observed was the contrast between students pursuing these three degrees and students in pursuit of a medical degree, whereas 
students pursuing the former experienced more self-determination than the latter group. It would be interesting to examine this further in undergraduate programs emphasizing prehealth professions. It is possible that the aspirations and regulators for these individuals may differ from this study population as the sub-discipline has slightly different sociocultural values. It is plausible that a unique culture exists among undergraduate premed students who aspire to be physicians. Specifically, it would be interesting to observe any potential conceptual shifts for those pre-health profession students who engage in biological research.

\section{Further Applications}

The alignment of the many constructs with SDT suggests that this macrotheory of human motivation is useful in capturing the variation associated with UREs. This framework aims at creating a broad model which can measure the benefits of undergraduate research on the development of scientific identity and their persistence in STEM. Integration of self-determination theory allows us to measure how the basic psychological needs of autonomy, competence, and relatedness are supported in these programs. As students progress within scientific disciplines, they will face ever increasing challenges in coursework and research. By integrating the promotion of selfdetermined behavior into undergraduate research programs, students will perceive science as an integral component of their personal identity. More qualitative work is required to further characterize the relationship of these constructs for undergraduate research. While this study focused primarily on students conducting ecological research, it may be important to expand the target population to include additional life science 
disciplines which emphasize on undergraduate research (physiology, cellular biology, neuroscience, biotechnology, etc.).

Ultimately this model will be able to identify programs which utilize varying practices to promote the development of scientific identity. In doing so, this can help identify resources that motivate students toward STEM careers and enable students, and particularly those from historically under-represented groups to reach their potential in STEM disciplines. It may also help guide administrators for the implementation of different intervention strategies. The design of this survey helps account for the withinsubject variability, allows for meaningful conclusions with smaller sample sizes, and may prove a valuable evaluation tool small programs such as UREs.

\section{ACKNOWLEDGMENTS}

This project was approved and monitored by the Illinois State University Institutional Review Board: IRB\# 2015-0244.

\section{REFERENCES}

Adams WK, Perkins KK, Podolefsky NS, Dubson M, Finkelstein ND, Wieman CE. 2006. New instrument for measuring student beliefs about physics and learning physics: The colorado learning attitudes about science survey. Phys Rev PER 2(1):010101.

Adams WK, Wieman CE, Perkins KK, Barbera J. 2008. Modifying and validating the colorado learning attitudes about science survey for use in chemistry. J Chem Educ 85(10):1435.

Bandura A. 1977. Self-efficacy: Toward a unifying theory of behavioral change. Psychol $\operatorname{Rev} 84(2): 191$. 
Bergsteiner H, Avery GC, Neumann R. 2010. Kolb's experiential learning model: Critique from a modelling perspective. Stud Contin Educ 32(1):29-46.

Box S, Cotgrove S. 1966. Scientific identity, occupational selection, and role strain. Br J Sociol 17(1):20-28.

Brown CJ, Hansen-Brown LJ, Conte R. 2011. Engaging millennial college-age science and engineering students through experiential learning communities. J Appl Global Res 4(10):41-58.

Cohen J. 1992. A power primer. Psychol Bull 112(1):155-159.

Courtney MGR, Gordon M. 2013. Determining the number of factors to retain in efa: Using the spss r-menu v2. 0 to make more judicious estimations. Pract Assess Res Eval 18(8):1-14.

Deci EL, Ryan RM. 2000a. Self-determination theory and the facilitation of intrinsic motivation, social development, and well-being. Am Psychol 55(1):68-78.

Deci EL, Ryan RM. 2000b. The "what" and "why" of goal pursuits: Human needs and the self-determination of behavior. Psychol Inq. 11(4):227-268.

Deci EL, Ryan RM. 2008. Self-determination theory: A macrotheory of human motivation, development, and health. Can Psychol 49(3):182-185.

DiStefano C, Zhu M, Mindrila D. 2009. Understanding and using factor scores: Considerations for the applied researcher. Pract Assess Res Eval 14(20):1-11.

Fabrigar LR, Wegener DT, MacCallum RC, Strahan EJ. 1999. Evaluating the use of exploratory factor analysis in psychological research. Psychol Methods. 4(3):272.

Gasiewski J, Eagan MK, Garcia G, Hurtado S, Chang M. 2012. From gatekeeping to engagement: A multicontextual, mixed method study of student academic engagement in introductory stem courses. Res High Educ 53(2):229-261. 
Gazley JL, Remich R, Naffziger-Hirsch ME, Keller J, Campbell PB, McGee R. 2014. Beyond preparation: Identity, cultural capital, and readiness for graduate school in the biomedical sciences. J Res Sci Teach 51(8):1021-1048.

Guay F, Ratelle CF, Chanal J. 2008. Optimal learning in optimal contexts: The role of self-determination in education. Can Psychol 49(3):233.

Harsh JA, Maltese AV, Tai RH. 2011. Undergraduate research experiences from a longitudinal perspective. J Coll Sci Teach 41(1):84-91.

Heddy BC, Sinatra GM. 2013. Transforming misconceptions: Using transformative experience to promote positive affect and conceptual change in students learning about biological evolution. Sci Educ 97(5):723-744.

Hill C, Corbett C, St. Rose A. 2010. Why so few? Women in science, technology, engineering, and mathematics. Washington, DC: American Association of University Women.

Hurtado S, Cabrera NL, Lin MH, Arellano L, Espinosa LL. 2008. Diversifying science: Underrepresented student experiences in structured research programs. Res High Educ 50(2):189-214.

Itin CM. 1999. Reasserting the philosophy of experiential education as a vehicle for change in the 21st century. J Exp Educ 22(2):91-98.

. Determining the dimensionality of data: A sas macro for parallel analysis. Proceedings of the 28th Annual Meeting of SAS Users Group International Seattle, WA Retrieved March; 2003.

Kasser T, Ryan RM. 1996. Further examining the american dream: Differential correlates of intrinsic and extrinsic goals. Pers Soc Psychol B 22(3):280-287.

Kline P. 2013. Intelligence: The psychometric view. New Youk, N.Y.: Routledge.

Kolb DA. 1984. Experiential learning: Experience as the source of learning and development. Englewood Cliffs, N.J.: Prentice-Hall. 
Korkmaz A, Cole JS, Buckley JA. 2011. Undergraduate research experience: Intention and doing for stem majors. Paper presented at: American Educational Research Association. New Orleans, LA.

Lopatto D. 2004. Survey of undergraduate research experiences (sure): First findings. CBE Life Sci Educ 3(4):270-277.

Lopatto D. 2007. Undergraduate research experiences support science career decisions and active learning. CBE Life Sci Educ 6(4):297-306.

Mackenzie SH, Son JS, Hollenhorst S. 2014. Unifying psychology and experiential education: Toward an integrated understanding of why it works. J Exp Educ $37(1): 75-88$.

Maw SJ, Mauchline AL, Park JR. 2011. Biological fieldwork provision in higher education. Biosci Educ 17(1):1-14.

Merton RK. 1968. Science and democratic social structure. Social theory and social structure. New York, N.Y.: The Free Press. p604-615.

Niemiec CP, Lynch MF, Vansteenkiste M, Bernstein J, Deci EL, Ryan RM. 2006. The antecedents and consequences of autonomous self-regulation for college: A selfdetermination theory perspective on socialization. J Adolesc 29(5):761-775.

Niemiec CP, Ryan RM. 2009. Autonomy, competence, and relatedness in the classroom applying self-determination theory to educational practice. Theory Res Educ 7(2):133-144.

Pelletier LG, Sharp E. 2008. Persuasive communication and proenvironmental behaviours: How message tailoring and message framing can improve the integration of behaviours through self-determined motivation. Can Psychol 49(3):210-217.

Pelletier LG, Tuson KM, Green-Demers I, Noles K, Beaton AM. 1998. Why are you doing things for the environment? The motivation toward the environment scale (mtes). J Appl Soc Psychol 28(5):437-468. 
Pugh K. 2002. Teaching for transformative experiences in science: An investigation of the effectiveness of two instructional elements. Teach Coll Rec 104(6):11011137.

Pugh KJ, Linnenbrink-Garcia L, Koskey KLK, Stewart VC, Manzey C. 2010. Motivation, learning, and transformative experience: A study of deep engagement in science. Sci Educ 94(1):1-28.

Reeve J, Halusic M. 2009. How k-12 teachers can put self-determination theory principles into practice. Theory Res Educ 7(2):145-154.

Ryan RM, Connell JP. 1989. Perceived locus of causality and internalization: Examining reasons for acting in two domains. J Pers Soc Psychol 57(5):749.

Sadler TD, Burgin S, McKinney L, Ponjuan L. 2010. Learning science through research apprenticeships: A critical review of the literature. J Res Sci Teach 47(3):235256.

Santos JRA. 1999. Cronbach's alpha: A tool for assessing the reliability of scales. J Extension. 37(2):1-5.

SAS Institute. 2014. Base sas 9.4 procedures guide. SAS Institute.

Scott GW, Goulder R, Wheeler P, Scott LJ, Tobin ML, Marsham S. 2012. The value of fieldwork in life and environmental sciences in the context of higher education: A case study in learning about biodiversity. J Sci Educ Technol 21(1):11-21.

Semsar K, Knight JK, Birol G, Smith MK. 2011. The colorado learning attitudes about science survey (class) for use in biology. CBE Life Sci Educ 10(3):268-278.

Soenens B, Vansteenkiste M. 2005. Antecedents and outcomes of self-determination in 3 life domains: The role of parents' and teachers' autonomy support. J Youth Adolesc 34(6):589-604.

Vallerand RJ, Fortier MS, Guay F. 1997. Self-determination and persistence in a real-life setting: Toward a motivational model of high school dropout. J Pers Soc Psychol 72(5):1161. 
Vansteenkiste M, Ryan RM. 2013. On psychological growth and vulnerability: Basic psychological need satisfaction and need frustration as a unifying principle. $\mathrm{J}$ Psychother Integr 23(3):263-280.

Villacorta M, Koestner R, Lekes N. 2003. Further validation of the motivation toward the environment scale. Environ Behav 35(4):486-505.

Wehmeyer ML, Agran M, Hughes C. 2000. A national survey of teachers' promotion of self-determination and student-directed learning. J Spec Educ 34(2):58-68. 
Table 1. Summary of category variables

\begin{tabular}{|c|c|c|c|c|c|c|c|c|c|}
\hline Variable & \multicolumn{3}{|c|}{ Number of Items } & \multicolumn{3}{|c|}{ Mean (SD) } & \multicolumn{3}{|c|}{ Cronbach's Alpha } \\
\hline Intrinsic Motivation & \multicolumn{3}{|c|}{4} & \multicolumn{3}{|c|}{$5.66(1.14)$} & \multicolumn{3}{|c|}{0.91} \\
\hline Integrated Regulation & \multicolumn{3}{|c|}{4} & \multicolumn{3}{|c|}{$5.36(1.33)$} & \multicolumn{3}{|c|}{0.85} \\
\hline Identified Regulation & \multicolumn{3}{|c|}{5} & \multicolumn{3}{|c|}{$5.13(1.02)$} & \multicolumn{3}{|c|}{0.85} \\
\hline Introjected Regulation & \multicolumn{3}{|c|}{5} & \multicolumn{3}{|c|}{$4.02(1.19)$} & \multicolumn{3}{|c|}{0.75} \\
\hline Extrinsic Regulation & \multicolumn{3}{|c|}{4} & \multicolumn{3}{|c|}{$3.25(1.34)$} & \multicolumn{3}{|c|}{0.79} \\
\hline Amotivation & \multicolumn{3}{|c|}{4} & \multicolumn{3}{|c|}{$1.79(1.07)$} & \multicolumn{3}{|c|}{0.89} \\
\hline Mentor Interest & \multicolumn{3}{|c|}{6} & \multicolumn{3}{|c|}{$5.63(1.04)$} & \multicolumn{3}{|c|}{0.88} \\
\hline Mentor Autonomy Support & \multicolumn{3}{|c|}{9} & \multicolumn{3}{|c|}{$5.73(0.96)$} & \multicolumn{3}{|c|}{0.90} \\
\hline Mentor Warmth & \multicolumn{3}{|c|}{6} & \multicolumn{3}{|c|}{$5.79(1.01)$} & \multicolumn{3}{|c|}{0.89} \\
\hline Associates Degree & & 3 & & & $11.56(8.10)$ & & & 0.95 & \\
\hline Bachelor's Degree & & 3 & & & $19.18(2.77)$ & & & 0.76 & \\
\hline Master's Degree & & 3 & & & $12.46(5.11)$ & & & 0.81 & \\
\hline $\mathrm{PhD}$ & & 3 & & & $10.31(4.66)$ & & & 0.77 & \\
\hline MD & & 3 & & & $6.14(5.52)$ & & & 0.93 & \\
\hline Real World Connections & & 7 & & & $4.04(0.44)$ & & & 0.84 & \\
\hline Enjoyment & & 6 & & & $4.34(0.68)$ & & & 0.87 & \\
\hline Reasoning & & 5 & & & $3.67(0.38)$ & & & 0.77 & \\
\hline Synthesis \& Application & & 7 & & & $3.79(0.63)$ & & & 0.80 & \\
\hline Strategy & & 4 & & & $3.94(0.52)$ & & & 0.64 & \\
\hline Effort & & 7 & & & $4.00(0.54)$ & & & 0.80 & \\
\hline Conceptual Connections & & 8 & & & $4.10(0.51)$ & & & 0.78 & \\
\hline & I & $\mathrm{L}$ & A & I & $\mathrm{L}$ & $\mathrm{A}$ & I & $\mathrm{L}$ & $\mathrm{A}$ \\
\hline Wealth & 5 & 5 & 5 & $3.36(1.22)$ & $3.18(1.12)$ & $2.08(0.87)$ & 0.84 & 0.82 & 0.72 \\
\hline Fame & 5 & 5 & 5 & $2.54(1.10)$ & $2.34(1.00)$ & $1.77(0.78)$ & 0.84 & 0.86 & 0.82 \\
\hline Image & 5 & 5 & 5 & $2.55(1.22)$ & $2.70(1.25)$ & $2.51(1.17)$ & 0.81 & 0.79 & 0.75 \\
\hline Personal Growth & 5 & 5 & 5 & $6.49(0.55)$ & $5.88(0.86)$ & $4.52(1.12)$ & 0.65 & 0.75 & 0.75 \\
\hline Relationships & 5 & 5 & 5 & $6.49(0.65)$ & $5.83(1.02)$ & $4.84(1.54)$ & 0.77 & 0.86 & 0.88 \\
\hline Community & 5 & 5 & 5 & $6.05(0.92)$ & $5.40(1.04)$ & $3.84(1.24)$ & 0.86 & 0.86 & 0.86 \\
\hline
\end{tabular}



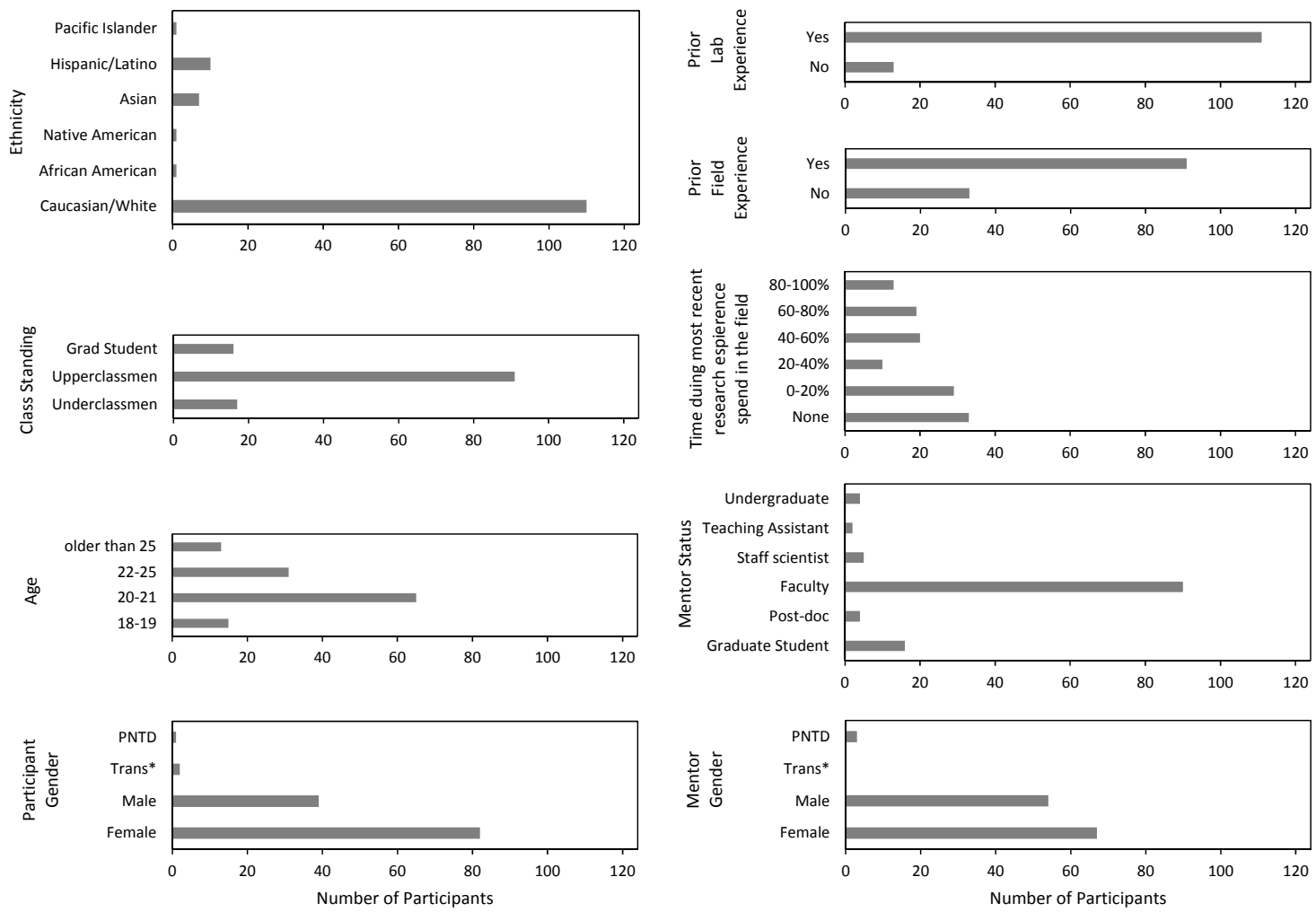

Figure 1. Demographic Information. Different questions were asked to understand the background and experiences of the respondents $(n=124)$. 


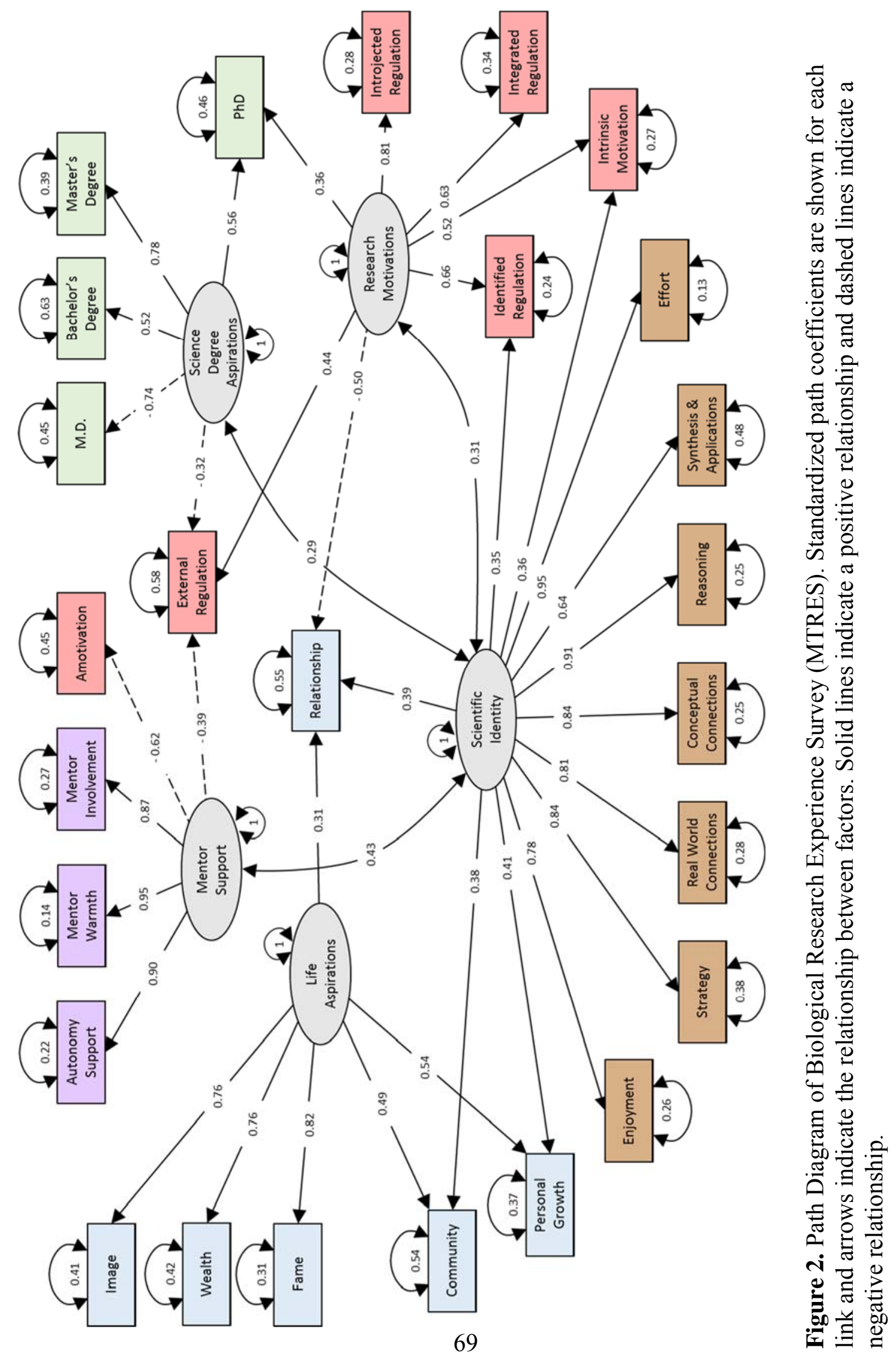



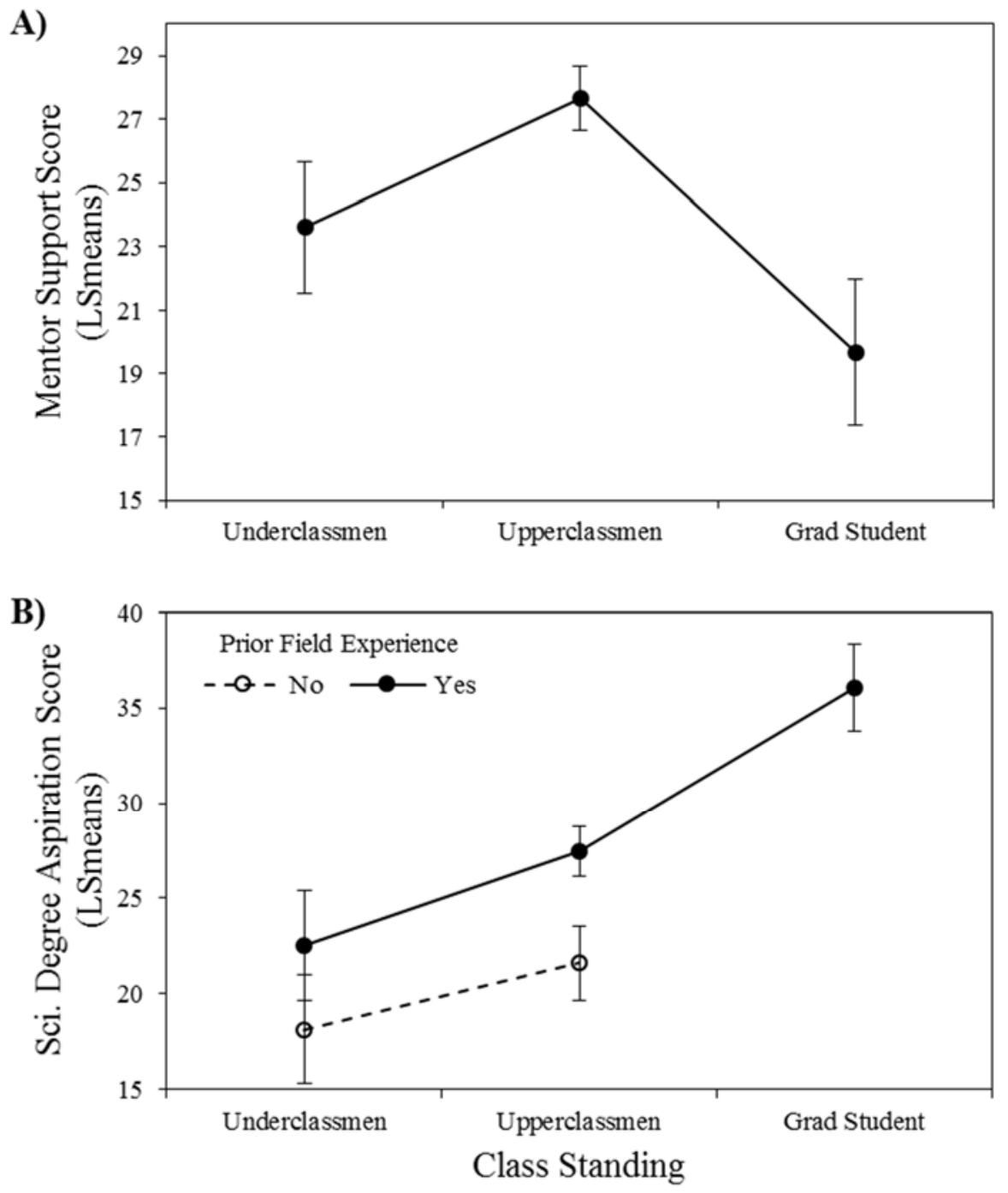

Figure 3. Comparison of Latent Variables Based on Class Standing. Panel A, illustrates a significant difference in scores between upperclassmen and graduate students, however, underclassmen didn't show a difference between either groups. In Panel B, class standing is further split based on the presence (closed) or absence (open) of prior field research. Graduate students had significantly higher scores than both undergraduate groups. Overall, students with prior field research experience had higher science degree aspiration scores than compared to those without prior experience. 


\section{CHAPTER III}

\section{FUTURE DIRECTIONS}

The previous two chapters demonstrated that 1) self-determination theory (SDT) is a viable lens for examining undergraduate research experiences (UREs) and 2) that existing SDT instruments can be adapted and combined to understand the complex nature of UREs. The first round of deployment for the Biological Research Experience Survey (BRES) was seen as a successful first step. Due to the exhaustive nature of the survey, 124 full participants exceeded the initial expectations and exhibited strong correlations among factors. The maximum likelihood approach for factor analysis, compared to principle axis factoring, requires an increased sample size and would allow for the generation of confidence intervals which would enable us to make broader claims about the nature of UREs within the biological sciences.

As we expand the scope of BRES, it would be prudent to target specific demographics and program types. Although our participants were somewhat representative of the greater biological research community, many minority ethnic groups were represented by only a few individuals. Additional efforts should be made to target these underrepresented groups to see if there are structural differences in how these 27 constructs represent these students' research experiences. Similar efforts should also be made for understanding the relationship of these structures for underclassmen and additional program types. The recent deployment offered a very little incentive for 
participants and could have led to a self-selection bias towards more intrinsically motivated individuals. Partnering with program coordinators appeared to help this potential bias and hopefully this data will be beneficial in recruiting additional program partners.

The BRES has the potential to become a powerful evaluation tool for many research programs. Other than extensive qualitative studies, for which many biologists are unfamiliar with their design and implementation, there are limited tools available to research coordinators that can evaluate the types of constructs within BRES. For many of these programs the act of learning to conduct research, and often the subsequential development of scientific identity can be prioritized over the productivity of research products. An eventual transition of the BRES to a pre/post design and could help demonstrate justification for programs whose teaching values align with the promotion of self-determined behavior. Hopefully by that time a prioritization of questions could be completed as to reduce the extensiveness of the survey and therefore to increase the practicality. To aid in these improvements, additional qualitative studies could be performed to test the causal relationships between the latent factors.

In addition to these refinements, the BRES could also expand to examine UREs in other scientific disciplines. It is currently targeted towards biology UREs due to the use of the CLASS-Bio (Semsar, Knight, Birol, and Smith, 2011), however, it could easily pivot towards other disciplines with CLASS instruments such as physics (Adams et al., 2006) and chemistry (Adams, Wieman, Perkins, \& Barbera, 2008). SDT is a broad theoretical framework for human emotion, and it is very likely that this transition to other 
disciplines would fall within the same general lens. Hopefully, as its application towards UREs expands, it will provide a more meaningful and tangible understanding for both researchers as well as practitioners.

\section{References}

Adams, W. K., Perkins, K. K., Podolefsky, N. S., Dubson, M., Finkelstein, N. D., \& Wieman, C. E. (2006). New instrument for measuring student beliefs about physics and learning physics: The Colorado Learning Attitudes about Science Survey. Physical Review Special Topics-Physics Education Research, 2(1), 010101.

Adams, W. K., Wieman, C. E., Perkins, K. K., \& Barbera, J. (2008). Modifying and validating the Colorado Learning Attitudes about Science Survey for use in chemistry. Journal of Chemical Education, 85(10), 1435.

Semsar, K., Knight, J. K., Birol, G., \& Smith, M. K. (2011). The Colorado Learning Attitudes about Science Survey (CLASS) for Use in Biology. CBE Life Sciences Education, 10(3), 268-278. doi: 10.1187/cbe.10-10-0133 


\section{APPENDIX A GUIDING QUESTIONS FOR INTERVIEWS}

1. What types of activities come to mind when I mention hands-on learning?

2. What are some notable examples of hands-on learning that you have experienced?

3. How closely do these experiences relate to your background within the biological sciences?

4. To what extent did these experiences help determine your discipline choice/direction?

5. Are there additional factors that helped determine your discipline choice/direction?

6. How do these hands-on experiences relate to your career aspirations?

7. What type of factors would you say drive your career aspirations?

8. How equipped do you feel you are to achieve your aspirations?

9. Are there programs or areas in which you would like additional support that would help you reach/determine your discipline or career choice?

10. How do you believe these types of activities should be incorporated into undergraduate curriculum?

11. Is there anything else that you would like to share that we didn't already cover? 
APPENDIX B

BIOLOGICAL RESEARCH EXPERIENCE SURVEY DESCRIPTION

\begin{tabular}{ll}
\hline \multicolumn{2}{l}{ Table B1. Demographic information } \\
\hline Question \# & \multicolumn{1}{c}{ Question Description } \\
\hline 1 & $\begin{array}{l}\text { What is your class standing? [Freshman; Sophomore; Junior; Senior/5th } \\
\text { Year Senior] }\end{array}$ \\
3 & How old are you? [18-19; 20-21; 22-25; older than 25] \\
4 & I identify my gender as... [Male; Female; Trans*; Prefer not to disclose] \\
& What race/ethnicity do you most identify as? [Caucasian/white; African \\
5 & American, Native American, Asian, Hispanic, Pacific Islander, Other] \\
6 & What is your current declared major? [text box] \\
& If you plan to change your major, please choose the major you intend to \\
& switch to: [text box]
\end{tabular}

\begin{tabular}{ll}
\hline Table B2. Undergraduate Research Experiences \\
\hline Question \# & \multicolumn{1}{c}{ Question Description } \\
\hline 7.0 & Have you ever conducted laboratory research? [Yes; No] \\
Prompt & If yes, how many of the following have you experienced? \\
7.1 & [Participant inserts integer] Volunteer/shadowing \\
7.2 & [Participant inserts integer] Coursework related \\
7.3 & [Participant inserts integer] Internship \\
7.4 & [Participant inserts integer] REU or other summer programs \\
7.5 & [Participant inserts integer] One-on-on mentored research \\
7.6 & [Participant inserts integer] Senior thesis/capstone experience \\
7.7 & [Participant inserts integer] Other: \\
8.0 & Have you ever conducted field research? [Yes; No] \\
Prompt & If yes, how many of the following have you experienced? \\
8.1 & [Participant inserts integer] Volunteer/shadowing \\
8.2 & [Participant inserts integer] Coursework related \\
8.3 & [Participant inserts integer] Internship \\
8.4 & [Participant inserts integer] REU or other summer programs \\
8.5 & [Participant inserts integer] One-on-on mentored research \\
8.6 & [Participant inserts integer] Senior thesis/capstone experience \\
8.7 & [Participant inserts integer] Other: \\
\hline
\end{tabular}


Table B3. Current or most recent Field Research Experience

\begin{tabular}{|c|c|}
\hline Question \# & Question Description \\
\hline 9.0 & $\begin{array}{l}\text { To what extent does your current or most recent field research experience } \\
\text { require you to go out into the field (away from a classroom, computer or } \\
\text { laboratory setting)? [80-100\%; 60-80\%; } 40-60 \% ; 20-40 \% ; 0-20 \% \text {; I do not } \\
\text { conduct field research at all] }\end{array}$ \\
\hline 10.0 & $\begin{array}{l}\text { Which of the following best describes your current or most recent } \\
\text { Undergraduate Research Experience? [Multiple-multiple choice] }\end{array}$ \\
\hline 10.1 & Volunteer/shadowing \\
\hline 10.2 & Coursework related \\
\hline 10.3 & Internship \\
\hline 10.4 & REU or other summer programs \\
\hline 10.5 & One-on-on mentored research \\
\hline 10.6 & Senior thesis/capstone experience \\
\hline 10.7 & Other: \\
\hline 11.0 & $\begin{array}{l}\text { Are you receiving any compensation for this research? [Academic credit; } \\
\text { Work-study (paid); Paid internship; Unpaid internship; Other, please } \\
\text { specify] }\end{array}$ \\
\hline Prompt $^{1}$ & $\begin{array}{l}\text { Why Are You Engaging In An Undergraduate Research Project? } \\
\text { Consider your current or most recent research project while you complete } \\
\text { the following section of the questionnaire. Listed below are several } \\
\text { statements concerning possible reasons why people might conduct } \\
\text { undergraduate research. Using the scale from 1-7 [1-Very untrue of me; 2- } \\
\text { Untrue of me; 3-Somewhat untrue of me; 4-Neutral; 5-Somewhat true of } \\
\text { me; 6-True of me; 7-Very true of me], please indicate the degree to which } \\
\text { the proposed reasons correspond to your reasons for doing undergraduate } \\
\text { research by circling the appropriate number to the right of the item. }\end{array}$ \\
\hline 12 & For the pleasure, I experience while I am mastering new skills. \\
\hline 13 & $\begin{array}{l}\text { Because I'm not satisfied with myself when I don't do any scientific } \\
\text { research. }\end{array}$ \\
\hline 14 & $\begin{array}{l}\text { For the pleasure, I experience when I find new ways to contribute to } \\
\text { scientific understanding. }\end{array}$ \\
\hline 15 & $\begin{array}{l}\text { Because it is a reasonable thing to do to contribute to scientific } \\
\text { understanding. }\end{array}$ \\
\hline 16 & $\begin{array}{l}\text { Because I like the feeling I have when I do things to contribute to scientific } \\
\text { understanding. }\end{array}$ \\
\hline 17 & I don't really know; I can't see what I'm getting out of it. \\
\hline 18 & I think I'd regret not doing something like this research project. \\
\hline 19 & $\begin{array}{l}\text { I wonder why I'm doing this research experience; it is simply not } \\
\text { supporting my career goals. }\end{array}$ \\
\hline 20 & For the pleasure, I get from contributing to scientific understanding. \\
\hline 21 & $\begin{array}{l}\text { Because it's a sensible thing to do in order to improve the quality of } \\
\text { scientific understanding. }\end{array}$ \\
\hline 22 & Because it's a way I've chosen to contribute to the scientific community. \\
\hline
\end{tabular}




\begin{tabular}{|c|c|}
\hline Question \# & Question Description \\
\hline 23 & $\begin{array}{l}\text { Because I'd feel I wouldn't be doing the right thing if I was neglecting to do } \\
\text { things that contribute to scientific understanding. }\end{array}$ \\
\hline 24 & Because other people (colleagues/mentors/students) will be upset if I don't. \\
\hline 25 & For the recognition, I get from others (colleagues/mentors/other students). \\
\hline 26 & $\begin{array}{l}\text { Because I would feel bad if I didn't do anything to contribute to the } \\
\text { advancement of science. }\end{array}$ \\
\hline 27 & $\begin{array}{l}\text { Because contributing to scientific understanding is an integral part of my } \\
\text { life right now }\end{array}$ \\
\hline 28 & Because my professor/mentor/colleague insists that I do it. \\
\hline 29 & $\begin{array}{l}\text { Because it seems to me that taking care of my career and taking care of this } \\
\text { research project are inseparable. }\end{array}$ \\
\hline 30 & Because I would feel guilty if I didn't. \\
\hline 31 & Because being a scientist has become a fundamental part of who I am. \\
\hline 32 & Because it's part of the career path that I've chosen to follow. \\
\hline 33 & $\begin{array}{l}\text { Because I would feel ashamed of myself if I was doing nothing to } \\
\text { contribute to the advancement of scientific understanding. }\end{array}$ \\
\hline 34 & $\begin{array}{l}\text { Because I think it's a good idea to do something to contribute to scientific } \\
\text { understanding. }\end{array}$ \\
\hline 35 & Because it is what my professor/mentor/colleagues tells me to do. \\
\hline 36 & $\begin{array}{l}\text { Honestly, I don't know; I truly have the impression that I'm wasting my } \\
\text { time conducting this research. }\end{array}$ \\
\hline 37 & $\begin{array}{l}\text { I don't know; I can't see how my contributions to this research project are } \\
\text { helping my career }\end{array}$ \\
\hline
\end{tabular}

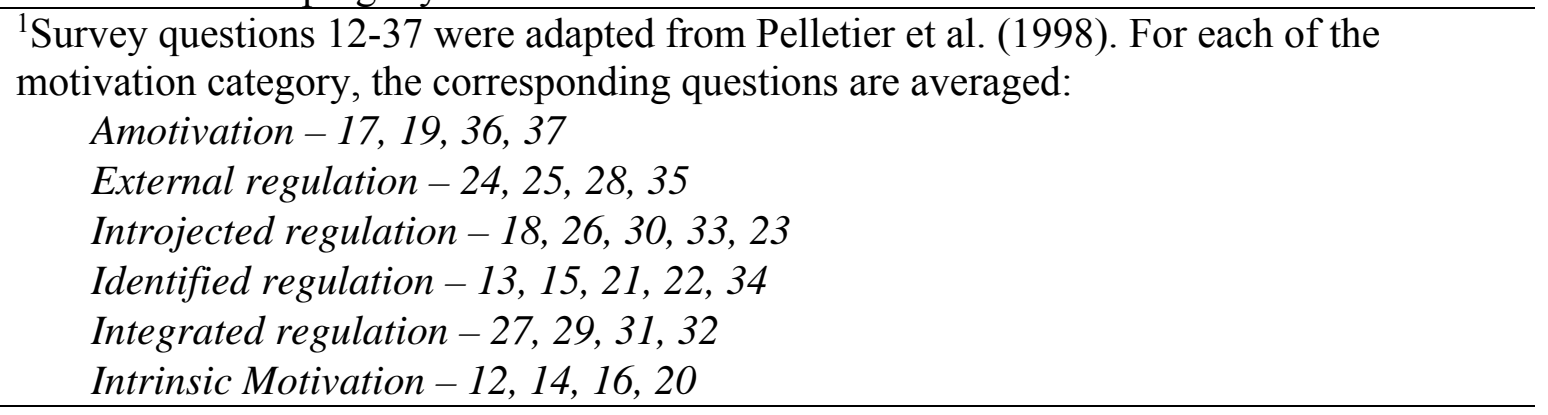


Table B4. Research Mentorship

\begin{tabular}{|c|c|}
\hline Question \# & Question Description \\
\hline 38 & $\begin{array}{l}\text { How would you describe your primary research mentor? (This is the person } \\
\text { whom you communicate most with about your project but may or may not } \\
\text { be the Primary Investigator) [Professor/Faculty member; Staff scientist; } \\
\text { Post-doc; Graduate Student; Teaching Assistant; Undergraduate Student; } \\
\text { Other, please specify] }\end{array}$ \\
\hline 39 & $\begin{array}{l}\text { What is the gender of your current or most recent research mentor? [Male; } \\
\text { Female; Trans*; Prefer not to disclose] }\end{array}$ \\
\hline Prompt $^{2}$ & $\begin{array}{l}\text { Please answer the following questions about your primary research mentor } \\
\text { (associated with your current or most recent research project) } \\
\text { Please use the following scale in answering each of these questions: } \\
\text { [1-Never true; 2-Rarely true; 3-Infrequently true; 4-Neutral; 5-Sometimes } \\
\text { true; 6-Usually true, 7-Always true] }\end{array}$ \\
\hline 40 & My mentor seems to know how I feel about things. \\
\hline 41 & My mentor tries to tell me how to run my life. \\
\hline 42 & My mentor finds time to talk with me. \\
\hline 43 & My mentor accepts me and likes me as I am. \\
\hline 44 & My mentor, whenever possible, allows me to choose what to do. \\
\hline 45 & My mentor doesn't seem to think of me often. \\
\hline 46 & My mentor clearly conveys his/her care for me. \\
\hline 47 & My mentor listens to my opinion or perspective when I've got a problem. \\
\hline 48 & My mentor spends a lot of time with me. \\
\hline 49 & My mentor makes me feel very special. \\
\hline 50 & My mentor allows me to decide things for myself. \\
\hline 51 & My mentor often seems too busy to attend to me. \\
\hline 52 & My mentor is often disapproving and unaccepting of me. \\
\hline 53 & My mentor insists upon my doing things his/her way. \\
\hline 54 & My mentor is not very involved with my concerns. \\
\hline 55 & My mentor is typically happy to see me. \\
\hline 56 & My mentor is usually willing to consider things from my point of view. \\
\hline 57 & My mentor puts time and energy into helping me. \\
\hline 58 & My mentor helps me to choose my own direction. \\
\hline 59 & My mentor seems to be disappointed in me a lot. \\
\hline 60 & My mentor isn't very sensitive to many of my needs. \\
\hline
\end{tabular}

${ }^{2}$ Survey questions 40-60 were adapted from Niemiec et al. (2006).For each of the mentorship category, the corresponding questions are averaged:

Mentor Involvement - 42, 45, 48, 51(R), 54(R), 57

Mentor Autonomy Support - 40, 41(R), 44, 47, 50, 53(R), 56, 58, 60(R)

Mentor Warmth - 43, 46, 49, 52(R), 55, 59(R) 
Table B5. Scientific Aspirations

\begin{tabular}{|c|c|}
\hline Question \# & Question Description \\
\hline Prompt $^{3}$ & $\begin{array}{l}\text { Everyone has long-term Goals or Aspirations. These are the things that } \\
\text { individuals hope to accomplish over the course of their lives. In this } \\
\text { section, you will find a number of life goals pertaining to education, } \\
\text { presented one at a time, and we ask you three questions about each goal: } \\
\text { (a) How important is this goal to you? } \\
\text { (b) How likely is it that you will attain this goal in your future? } \\
\text { (c) How much have you already achieved this goal thus far? } \\
\text { Please use the following scale in answering each of the three questions } \\
\text { about each life goal: [1-Not at all; 4-Moderately; 7-Very] }\end{array}$ \\
\hline Life-goal: & To obtain an associate's degree (or equivalent) in a STEM field. \\
\hline 61 & How important is this to you? \\
\hline 62 & How likely is it that this will happen for you? \\
\hline 63 & How much have you already attained this goal? \\
\hline Life-goal: & To obtain a bachelor's degree (or equivalent) in a STEM field. \\
\hline 64 & How important is this to you? \\
\hline 65 & How likely is it that this will happen for you? \\
\hline 66 & How much have you already attained this goal? \\
\hline Life-goal: & To obtain a master's degree (or equivalent) in a STEM field. \\
\hline 67 & How important is this to you? \\
\hline 68 & How likely is it that this will happen for you? \\
\hline 69 & How much have you already attained this goal? \\
\hline Life-goal: & To obtain a PhD in a STEM field. \\
\hline 70 & How important is this to you? \\
\hline 71 & How likely is it that this will happen for you? \\
\hline 72 & How much have you already attained this goal? \\
\hline Life-goal: & To obtain a MD or equivalent health profession degree. \\
\hline 73 & How important is this to you? \\
\hline 74 & How likely is it that this will happen for you? \\
\hline 75 & How much have you already attained this goal? \\
\hline \multicolumn{2}{|c|}{$\begin{array}{l}\text { 'Survey questions } 61-75 \text { were adapted from Kasser and Ryan } \\
\text { degree category, the corresponding questions are summed: } \\
\text { Associate's Degree - 61, 62, } 63 \\
\text { Bachelor's Degree }-64,65,66 \\
\text { Master's Degree - 67, 68, } 69 \\
\text { PhD-70, 71, } 72 \\
M D-73,74,75\end{array}$} \\
\hline
\end{tabular}


Table B6. Beliefs About Learning Biology

\begin{tabular}{ll}
\hline Question \# & \multicolumn{1}{c}{ Question Description } \\
\hline Prompt & \\
& Here are a number of statements that may or may not describe your \\
beliefs about learning biology. You are asked to rate each statement by \\
selecting a number between 1 and 5 where the numbers mean the \\
following: [1-Strongly Disagree; 2-Disagree; 3-Neutral; 4-Agree; 5- \\
Strongly Agree] \\
My curiosity about the living world led me to study biology. \\
76 & $\begin{array}{l}\text { I think about the biology I experience in everyday life. } \\
\text { After I study a topic in biology and feel that I understand it, I have } \\
\text { difficulty applying that information to answer questions on the same }\end{array}$ \\
78 & $\begin{array}{l}\text { topic. } \\
\text { Knowledge in biology consists of many disconnected topics. }\end{array}$ \\
79 & $\begin{array}{l}\text { When I am answering a biology question, I find it difficult to put what I } \\
\text { know into my own words. }\end{array}$ \\
I do not expect the rules of biological principles to help my \\
understanding of the ideas. \\
To understand biology, I sometimes think about my personal \\
experiences and relate them to the topic being analyzed. \\
If I get stuck on answering a biology question on my first try, I usually \\
try to figure out a different way that works. \\
I want to study biology because I want to make a contribution to \\
society.
\end{tabular}




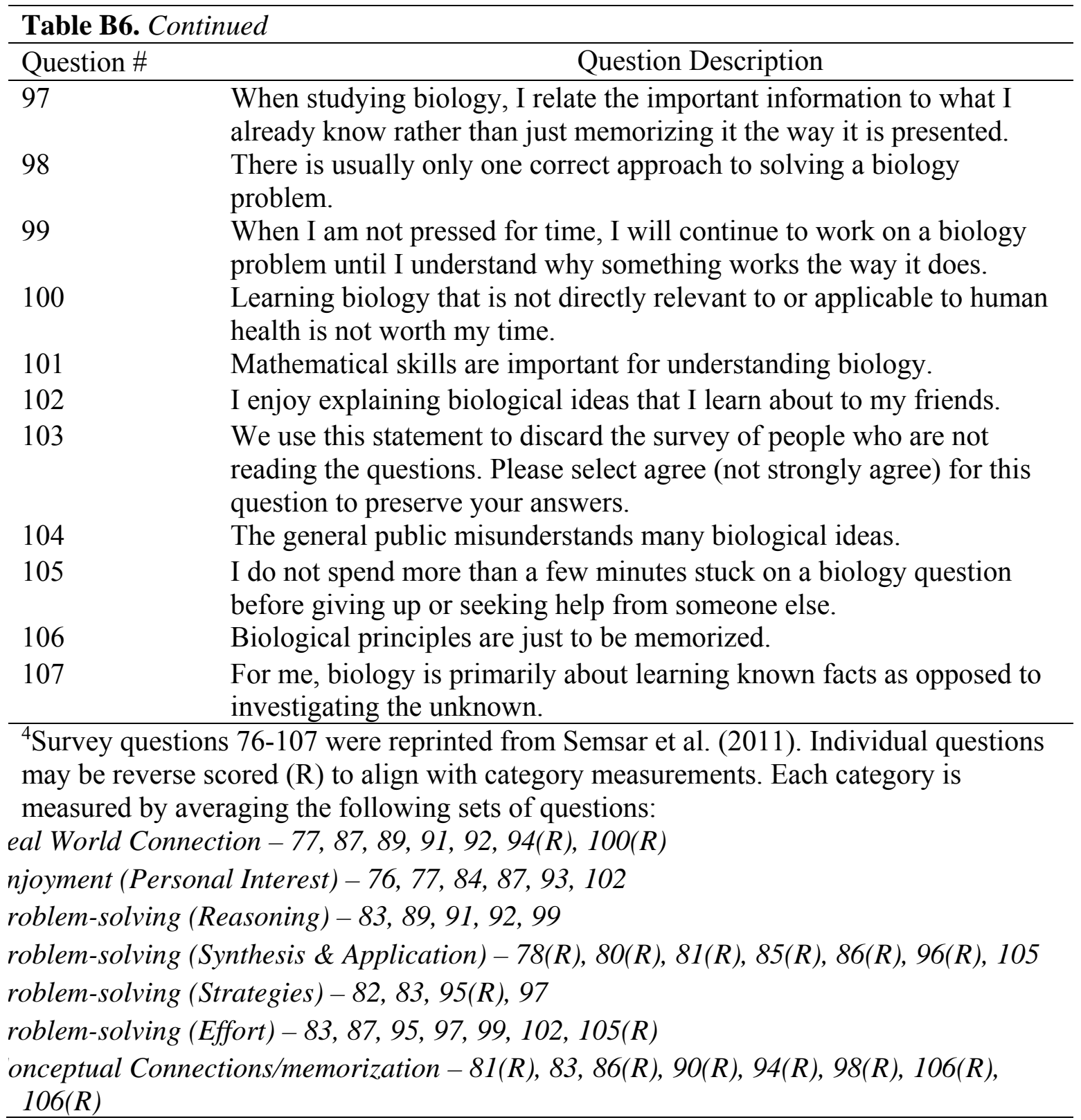


Table B7. Life Aspirations

\begin{tabular}{ll}
\hline Question \# & Question Description \\
\hline Prompt $^{5}$ & $\begin{array}{l}\text { Everyone has long-term Goals or Aspirations. These are the things that } \\
\text { individuals hope to accomplish over the course of their lives. In this } \\
\text { section, you will find a number of life goals pertaining to education, } \\
\text { presented one at a time, and we ask you three questions about each goal: }\end{array}$ \\
& $\begin{array}{l}\text { (a) How important is this goal to you? } \\
\text { (b) How likely is it that you will attain this goal in your future? }\end{array}$ \\
& $\begin{array}{l}\text { (c) How much have you already achieved this goal thus far? } \\
\text { Please use the following scale in answering each of the three questions }\end{array}$ \\
& about each life goal: [1-Not at all; 4-Moderately; 7-Very] \\
Life-goal: & To be a very wealthy person. \\
108 & How important is this to you? \\
109 & How likely is it that this will happen in your future? \\
110 & How much have you already attained this goal? \\
Life-goal: & To grow and learn new things. \\
111 & How important is this to you? \\
112 & How likely is it that this will happen in your future? \\
113 & How much have you already attained this goal? \\
Life-goal: & To have my name known by many people. \\
114 & How important is this to you? \\
115 & How likely is it that this will happen in your future? \\
116 & How much have you already attained this goal? \\
Life-goal: & To have good friends that I can count on. \\
117 & How important is this to you? \\
118 & How likely is it that this will happen in your future? \\
119 & How much have you already attained this goal? \\
Life-goal: & To work for the betterment of society. \\
120 & How important is this to you? \\
121 & How likely is it that this will happen in your future? \\
122 & How much have you already attained this goal? \\
Life-goal: & To have many expensive possessions. \\
123 & How important is this to you? \\
124 & How likely is it that this will happen in your future? \\
125 & How much have you already attained this goal? \\
Life-goal: & At the end of my life, to be able to look back on my life as meaningful and \\
126 & complete. \\
127 & How important is this to you? \\
128 & How likely is it that this will happen in your future? \\
Life-goal: & How much have you already attained this goal? \\
& To be admired by many people.
\end{tabular}




\begin{tabular}{ll}
\hline Table B7. & Continued \\
\hline Question \# & Question Description \\
\hline 129 & How important is this to you? \\
130 & How likely is it that this will happen in your future? \\
131 & How much have you already attained this goal? \\
Life-goal: & To share my life with someone I love. \\
132 & How important is this to you? \\
133 & How likely is it that this will happen in your future? \\
134 & How much have you already attained this goal? \\
Life-goal: & To have people comment often about how attractive I look. \\
135 & How important is this to you? \\
136 & How likely is it that this will happen in your future? \\
137 & How much have you already attained this goal? \\
Life-goal: & To assist people who need it, asking nothing in return. \\
138 & How important is this to you? \\
139 & How likely is it that this will happen in your future? \\
140 & How much have you already attained this goal? \\
Life-goal: & To be financially successful. \\
141 & How important is this to you? \\
142 & How likely is it that this will happen in your future? \\
143 & How much is this satisfied currently? \\
Life-goal: & To choose what I do, instead of being pushed along by life. \\
144 & How important is this to you? \\
145 & How likely is it that this will happen in your future? \\
146 & How much is this satisfied currently? \\
Life-goal: & To be famous. \\
147 & How important is this to you? \\
148 & How likely is it that this will happen in your future? \\
149 & How much have you already attained this goal? \\
Life-goal: & To have committed, intimate relationships. \\
150 & How important is this to you? \\
151 & How likely is it that this will happen in your future? \\
152 & How much have you already attained this goal? \\
Life-goal: & To keep up with fashions in hair and clothing. \\
153 & How important is this to you? \\
154 & How likely is it that this will happen in your future? \\
155 & How much have you already attained this goal? \\
Life-goal: & To work to make the world a better place. \\
156 & How important is this to you? \\
157 & How likely is it that this will happen in your future? \\
\hline &
\end{tabular}




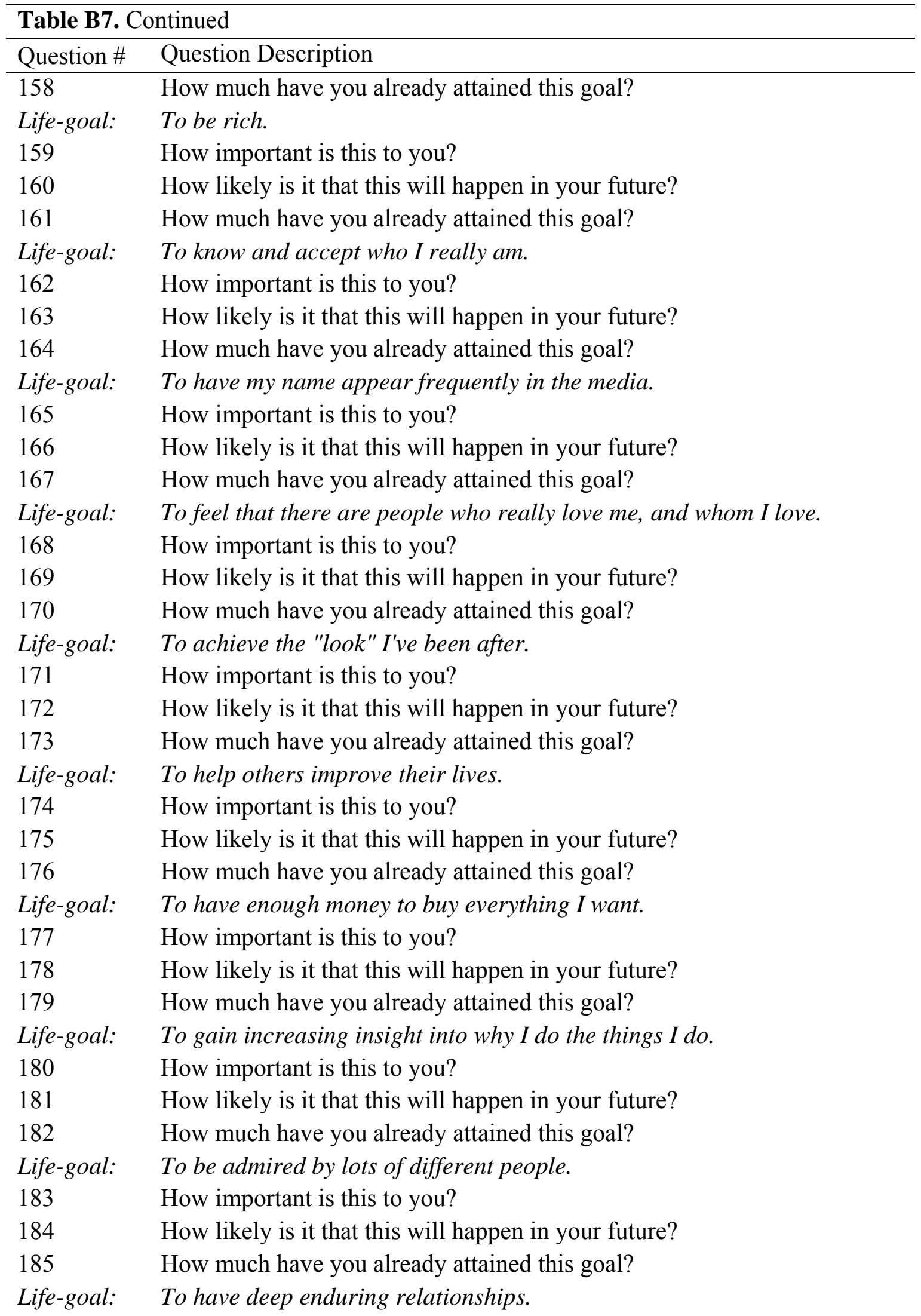




\begin{tabular}{ll}
\hline \multicolumn{2}{l}{ Table B7. Continued } \\
\hline Question \# & Question Description \\
\hline 186 & How important is this to you? \\
187 & How likely is it that this will happen in your future? \\
188 & How much have you already attained this goal? \\
Life-goal: & To have an image that others find appealing. \\
189 & How important is this to you? \\
190 & How likely is it that this will happen in your future? \\
191 & How much have you already attained this goal? \\
Life-goal: & To help people in need. \\
192 & How important is this to you? \\
193 & How likely is it that this will happen in your future? \\
194 & How much have you already attained this goal?
\end{tabular}

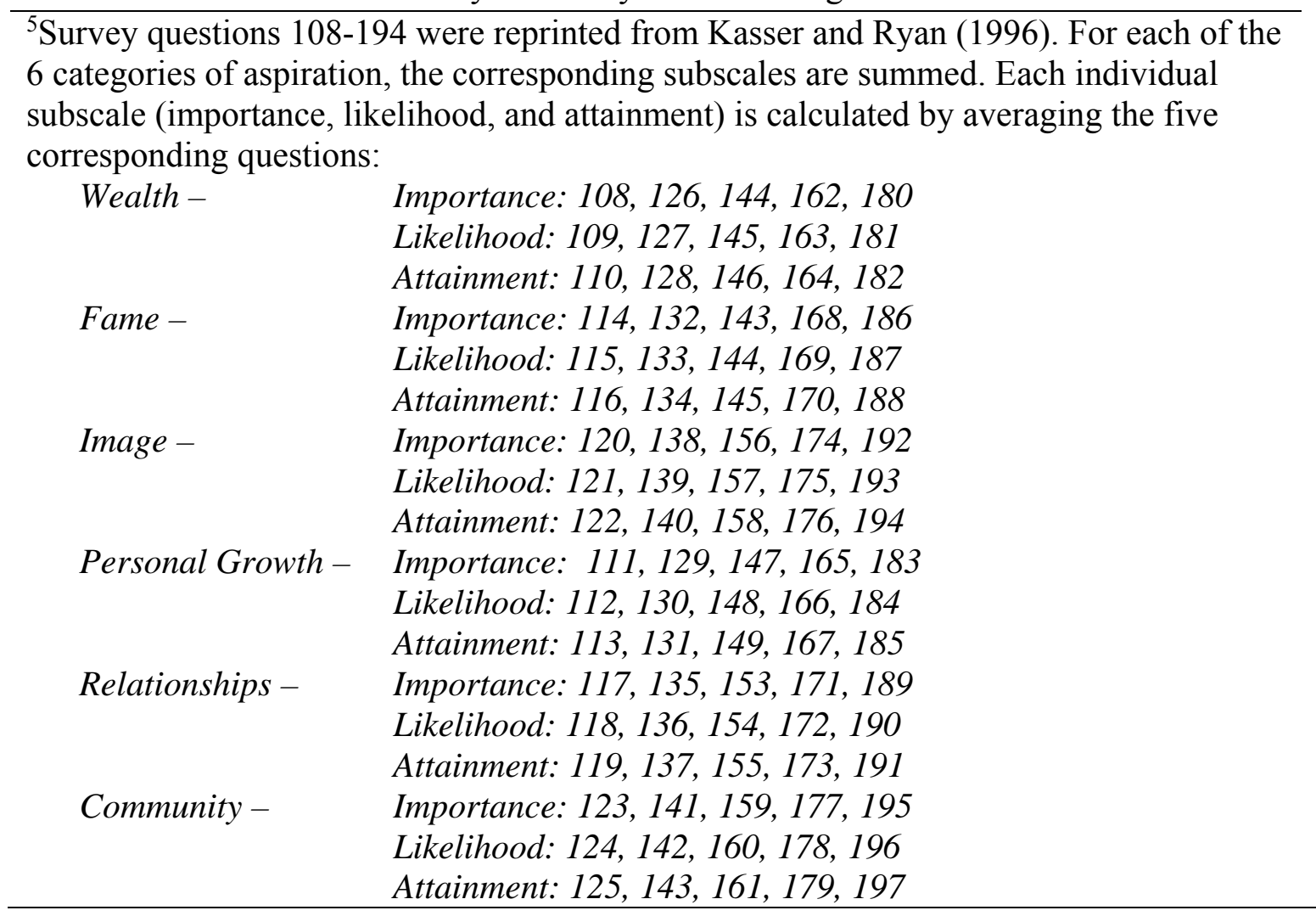

\section{REFERENCES}

Kasser T, Ryan RM. 1996. Further examining the american dream: Differential correlates of intrinsic and extrinsic goals. Personality and Social Psychology Bulletin. 22(3):280-287. 
Niemiec CP, Lynch MF, Vansteenkiste M, Bernstein J, Deci EL, Ryan RM. 2006. The antecedents and consequences of autonomous self-regulation for college: A selfdetermination theory perspective on socialization. Journal of adolescence. 29(5):761-775.

Pelletier LG, Tuson KM, Green-Demers I, Noles K, Beaton AM. 1998. Why are you doing things for the environment? The motivation toward the environment scale (mtes). Journal of Applied Social Psychology. 28(5):437-468.

Semsar K, Knight JK, Birol G, Smith MK. 2011. The colorado learning attitudes about science survey (class) for use in biology. CBE Life Sciences Education. 10(3):268-278. 


\section{APPENDIX C}

\section{CORRELATION MATRIX FOR EXPLORATORY FACTOR ANALYSIS}

\begin{tabular}{|c|c|c|c|c|c|c|}
\hline & 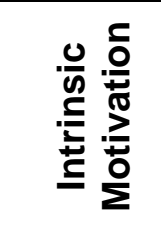 & 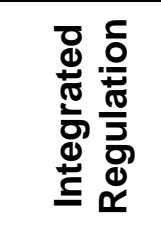 & 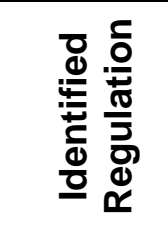 & 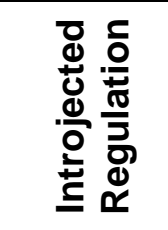 & 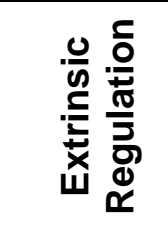 & 突 \\
\hline Intrinsic Motivation & 1 & & & & & \\
\hline Integrated Regulation & 0.72129 & 1 & & & & \\
\hline Identified Regulation & 0.81147 & 0.72179 & 1 & & & \\
\hline Introjected Regulation & 0.49167 & 0.52242 & 0.61465 & 1 & & \\
\hline Extrinsic Regulation & -0.16299 & -0.01939 & -0.02895 & 0.26545 & 1 & \\
\hline Amotivation & -0.50613 & -0.47455 & -0.34334 & -0.09493 & 0.3177 & 1 \\
\hline Wealth & -0.05498 & -0.07605 & -0.08738 & -0.13035 & 0.0487 & 0.13403 \\
\hline Fame & 0.05485 & 0.0708 & -0.02999 & 0.03873 & 0.1846 & -0.00867 \\
\hline Image & 0.15087 & 0.07324 & 0.07608 & 0.071 & 0.0591 & -0.05703 \\
\hline Personal Growth & 0.38829 & 0.21678 & 0.31131 & 0.08945 & -0.18748 & -0.29121 \\
\hline Relationships & 0.06432 & 0.0029 & 0.00557 & -0.12868 & -0.09742 & -0.00356 \\
\hline Community & 0.24169 & 0.10805 & 0.1366 & 0.06017 & -0.03668 & -0.24541 \\
\hline Mentor Interest & 0.26102 & 0.13663 & 0.21011 & 0.04698 & -0.15423 & -0.44658 \\
\hline $\begin{array}{l}\text { Mentor Autonomy } \\
\text { Support }\end{array}$ & 0.25803 & 0.22546 & 0.15246 & 0.04754 & -0.23567 & -0.48803 \\
\hline Mentor Warmth & 0.31876 & 0.24917 & 0.24722 & 0.10317 & -0.22385 & -0.52079 \\
\hline Associates Degree & 0.07476 & 0.11547 & 0.12241 & 0.04843 & 0.12337 & 0.07658 \\
\hline Bachelor's Degree & 0.34864 & 0.2453 & 0.30532 & 0.19733 & -0.1135 & -0.10496 \\
\hline Master's Degree & 0.22465 & 0.25666 & 0.15476 & 0.06957 & -0.20879 & -0.11059 \\
\hline PhD & 0.37176 & 0.43765 & 0.42598 & 0.32121 & 0.02132 & -0.25047 \\
\hline MD & 0.00686 & -0.09055 & 0.0128 & -0.08909 & 0.03816 & -0.04313 \\
\hline Real World Connections & 0.53299 & 0.49301 & 0.50616 & 0.27499 & -0.09497 & -0.43442 \\
\hline Enjoyment & 0.58795 & 0.56562 & 0.56924 & 0.35139 & -0.03014 & -0.34666 \\
\hline Reasoning & 0.47836 & 0.45225 & 0.47336 & 0.2452 & -0.06371 & -0.32387 \\
\hline Synthesis \& Application & 0.41982 & 0.33512 & 0.32971 & 0.15436 & -0.19059 & -0.38698 \\
\hline Strategy & 0.43817 & 0.34503 & 0.39388 & 0.1629 & -0.05641 & -0.23178 \\
\hline Effort & 0.60591 & 0.53864 & 0.59698 & 0.28188 & -0.10688 & -0.34944 \\
\hline Conceptual Connection & 0.49669 & 0.43562 & 0.49108 & 0.19285 & -0.18408 & -0.4167 \\
\hline
\end{tabular}


Table C1. Continued

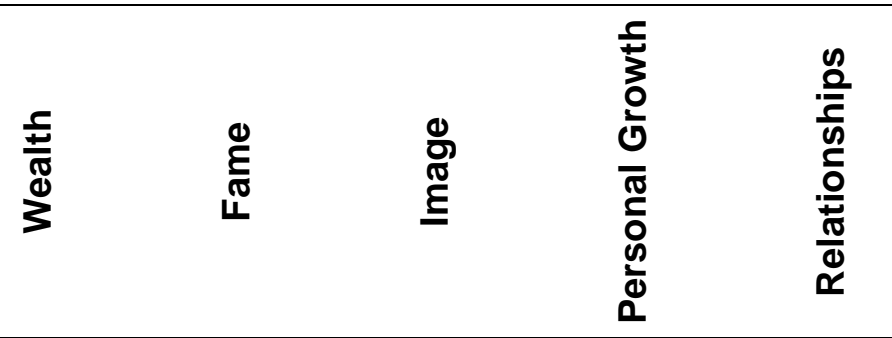

\begin{tabular}{lccccc}
\hline Intrinsic Motivation & & & & & \\
Integrated Regulation & & & & & \\
Identified Regulation & & & & & \\
Introjected Regulation & & & & & \\
Extrinsic Regulation & & & & & \\
Amotivation & & & & & \\
Wealth & 1 & & & & \\
Fame & 0.51994 & 1 & & & \\
Image & 0.5353 & 0.47893 & 1 & \\
Personal Growth & 0.2338 & 0.35987 & 0.29128 & & \\
Relationships & 0.12192 & 0.08538 & 0.1834 & 0.42204 & \\
Community & 0.123 & 0.30588 & 0.24453 & 0.52999 & 0.2595 \\
Mentor Interest & 0.02379 & -0.02987 & 0.05831 & 0.21717 & 0.01841 \\
Mentor Autonomy Support & -0.08113 & -0.00703 & 0.00226 & 0.30633 & 0.1858 \\
Mentor Warmth & 0.00967 & 0.01442 & 0.05866 & 0.30807 & 0.07618 \\
Associates Degree & -0.00866 & -0.08944 & 0.01313 & 0.02453 & 0.0125 \\
Bachelor's Degree & -0.06533 & -0.16783 & -0.05717 & 0.12785 & 0.06383 \\
Master's Degree & 0.04423 & 0.0085 & 0.12323 & 0.09417 & 0.09069 \\
PhD & 0.00808 & 0.04744 & 0.13632 & 0.19488 & 0.02456 \\
MD & 0.19141 & 0.12872 & 0.04668 & 0.08007 & -0.0866 \\
Real World Connections & -0.09424 & 0.00393 & 0.24468 & 0.34324 & 0.08528 \\
Enjoyment & -0.05516 & -0.04099 & 0.21111 & 0.31891 & 0.13152 \\
Reasoning & -0.0837 & -0.03425 & 0.10627 & 0.32124 & 0.12442 \\
Synthesis \& Application & -0.07729 & -0.08982 & -0.03765 & 0.33432 & 0.19562 \\
Strategy & -0.09316 & -0.10037 & 0.06411 & 0.36483 & 0.27641 \\
Effort & -0.08364 & -0.10026 & 0.05565 & 0.41689 & 0.23337 \\
Conceptual Connections & -0.12088 & -0.12385 & 0.06664 & 0.44011 & 0.20869 \\
\hline & & & & & \\
\hline
\end{tabular}


Table C1. Continued

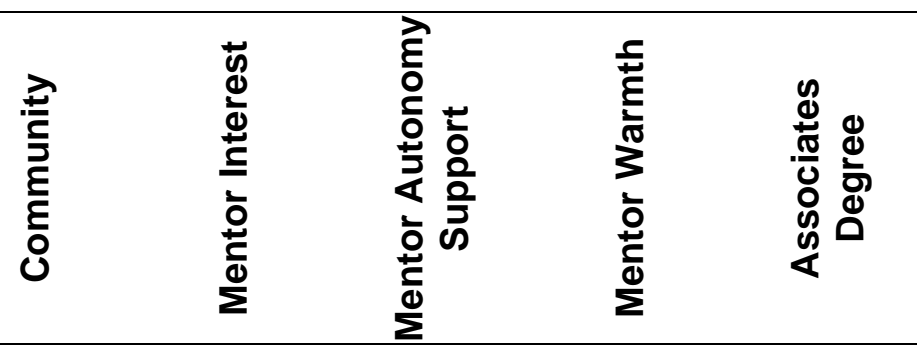

Intrinsic Motivation

Integrated Regulation

Identified Regulation

Introjected Regulation

Extrinsic Regulation

Amotivation

Wealth

Fame

Image

Personal Growth

Relationships

Community 1

Mentor Interest $\quad 0.14671 \quad 1$

Mentor Autonomy Support $\quad 0.12675 \quad 0.67845$

Mentor Warmth

$\begin{array}{llll}0.10938 & 0.79139 & 0.84458 & 1\end{array}$

Associates Degree

0.01053

$\begin{array}{lll}-0.05884 & -0.05605 & -0.0644\end{array}$

1

Bachelor's Degree

$-0.16707$

0.11277

0.0979

0.11382

0.12339

Master's Degree

0.07068

$-0.07404$

$-0.01462$

$-0.03508$

0.02442

PhD

0.01368

0.06858

0.23623

0.19428

0.11106

MD

0.28765

0.19266

$-0.00086$

0.12346

$-0.08834$

Real World Connections

0.23697

0.2749

0.25727

0.30839

0.07274

Enjoyment

0.20675

0.26112

0.21616

0.28308

0.10361

Reasoning

0.26282

0.22727

0.18701

0.25426

0.10621

Synthesis \& Application

0.10843

0.28831

0.28536

0.23864

0.0316

Strategy

0.22191

0.25719

0.35695

0.29137

0.15283

Effort

0.21987

0.26199

0.30289

0.28733

0.1167

Conceptual Connections

0.27636

0.26763

0.3036

0.25428

0.0713 
Table C1. Continued

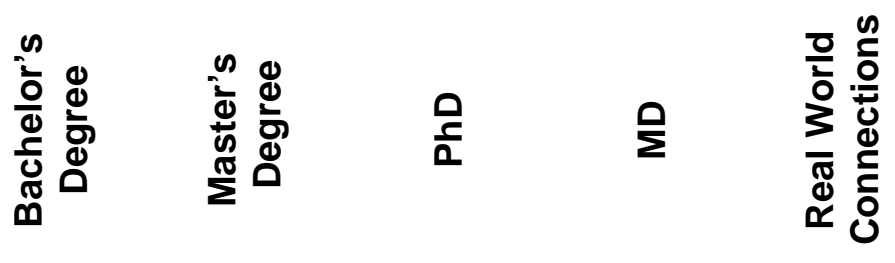

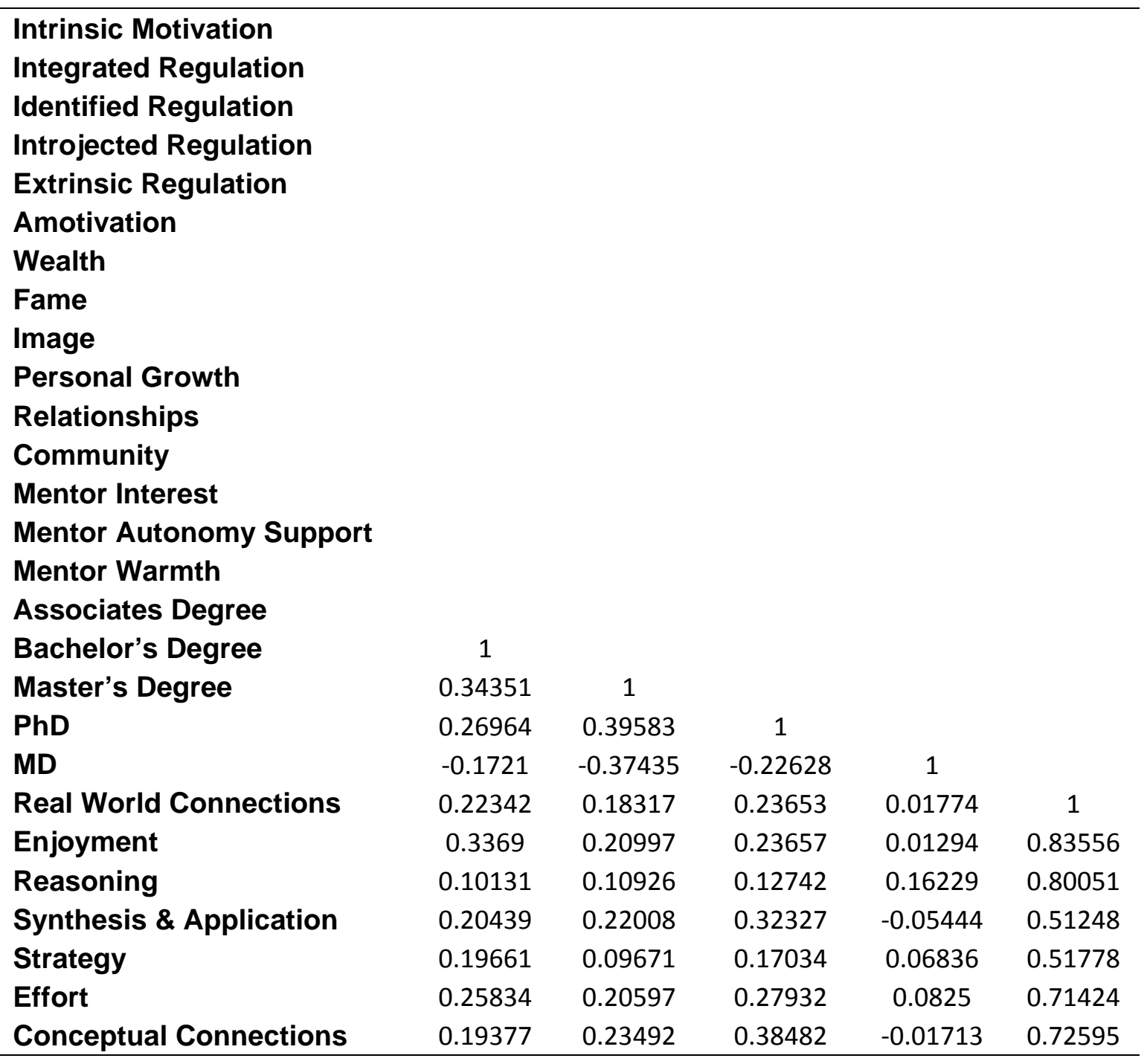


Table C1. Continued

\begin{tabular}{|c|c|c|c|c|}
\hline 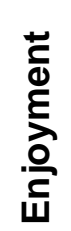 & 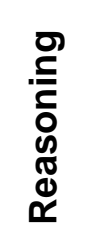 & 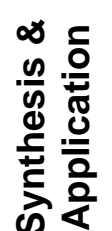 & 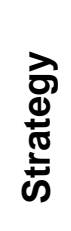 & $\begin{array}{l}\frac{ \pm}{0} \\
\frac{ \pm}{ \pm}\end{array}$ \\
\hline
\end{tabular}

Intrinsic Motivation

Integrated Regulation

Identified Regulation

Introjected Regulation

Extrinsic Regulation

Amotivation

Wealth

Fame

Image

Personal Growth

Relationships

Community

Mentor Interest

Mentor Autonomy Support

Mentor Warmth

Associates Degree

Bachelor's Degree

Master's Degree

PhD

MD

Real World Connections

\begin{tabular}{lcccccc} 
Enjoyment & 1 & & & & & \\
Reasoning & 0.68411 & 1 & & & & \\
Synthesis \& Application & 0.45044 & 0.44202 & 1 & & & \\
Strategy & 0.56998 & 0.59677 & 0.41498 & 1 & & \\
Effort & 0.7956 & 0.77742 & 0.63396 & 0.79789 & 1 & \\
Conceptual Connections & 0.62721 & 0.61554 & 0.75634 & 0.61477 & 0.74361 & 1 \\
\hline
\end{tabular}

